\title{
Changes in production work when using smart wearables-results of a Delphi-based study
}

\author{
Verena Blumberg ${ }^{1}$ Eva-Maria Schulte ${ }^{1}$ Simone Kauffeld ${ }^{1}$ \\ Accepted: 23 September 2021 / Published online: 13 October 2021 \\ (c) The Author(s) 2021
}

\begin{abstract}
In industrial production, smart wearables (e.g. data glasses) are becoming more relevant to support employees. While economic aspects have so far been the focus of the introduction, changes for work design have been neglected. The aim of the Delphi study was to describe changes through the use of smart wearables and to derive implications for work design. Six description dimensions (application, implications for work design, data use, personalization, flexibility, introductory purpose) were identified and 18 scenarios were developed. The assessment of the scenarios in terms of desirability and degree of dissemination showed that scenarios for work-related and ergonomic support are particularly desirable and scenarios for changes in cooperation are considered particularly likely. Data usage is a relevant factor for the assumed degree of dissemination but not for the assessment of desirability. In operational practice, work design and economic aspects are important for assessing the scenarios.

Practical Relevance: The results show possible development scenarios for production work when using smart wearables and highlight possible implications for work design. Positive and negative effects on task, knowledge, social and contextual characteristics are identified, which offer suggestions for a conscious selection and design of the use of technology in practice.
\end{abstract}

Keywords Digitalization $\cdot$ Smart wearables $\cdot$ Industry $4.0 \cdot$ Work design $\cdot$ Delphi method

\section{Veränderungen der Produktionsarbeit beim Einsatz von Smart Wearables - Ergebnisse einer Delphi-basierten Studie}

\section{Zusammenfassung}

In der industriellen Produktion werden Smart Wearables (z.B. Datenbrillen) zur Unterstützung der Mitarbeitenden relevanter. Während ökonomische Aspekte bei der Einführung bisher im Fokus standen, wurden Veränderungen für die Arbeitsgestaltung vernachlässigt. Ziel der Delphi-Studie war es, Veränderungen durch den Einsatz von Smart Wearables zu beschreiben und Implikationen zur Arbeitsgestaltung abzuleiten. Es wurden sechs Beschreibungsdimensionen (Anwendung, Implikationen für die Arbeitsgestaltung, Datennutzung, Personalisierung, Flexibilisierung, Einführungszweck) identifiziert und 18 Szenarien entwickelt. Die Einschätzung der Szenarien hinsichtlich Erwünschtheit und Verbreitungsgrad zeigte, dass Szenarien zur arbeitsbezogenen und ergonomischen Unterstützung als besonders erwünscht und Szenarien zu Veränderungen der Zusammenarbeit als besonders wahrscheinlich eingeschätzt werden. Die Datennutzung ist ein relevanter Faktor für den angenommenen Verbreitungsgrad, nicht jedoch für die Einschätzung der Erwünschtheit. In der betrieblichen Praxis sind u. a. die Arbeitsgestaltung und ökonomische Aspekte Schlüsselkriterien für die Einschätzung der Szenarien. Praktische Relevanz: Die Ergebnisse zeigen mögliche Entwicklungsszenarien für die Produktionsarbeit beim Einsatz von Smart Wearables auf und beleuchten mögliche Implikationen für die Arbeitsgestaltung. Dabei werden positive und negative Auswirkungen auf Aufgaben-, Wissens-, soziale und kontextuelle Merkmale herausgearbeitet, die Anregungen für eine bewusste Auswahl und Gestaltung des Technologieeinsatzes in der Praxis bieten.

Verena Blumberg

v.blumberg@tu-braunschweig.de
Institut für Arbeits-, Organisations- und Sozialpsychologie, Technische Universität Braunschweig, Braunschweig, Germany 
Schlüsselwörter Digitalisierung $\cdot$ Technologie $\cdot$ Industrie $4.0 \cdot$ Arbeitsgestaltung $\cdot$ Delphi-Methode

\section{Introduction}

Technological developments have always been a major driver of change in workplaces and work practices. Therefore, it is not surprising that technology is present as a relevant variable in many work design frameworks (Morgeson and Campion 2003; Morgeson et al. 2013; Parker et al. 2001, 2017). However, the recent increase in the digitalization of work, especially in industrial work, seems to be bringing about a new quality of change (Hirsch-Kreinsen 2016). These changes are summarized under the buzzword of Industry 4.0 or the "fourth industrial revolution" (Lasi et al. 2014). This describes a fundamental transformation of industrial work through an increasing data transfer between physical systems with embedded software and a global data network (Hirsch-Kreinsen 2016). Employees have to become part of this data network. Therefore, they will be ubiquitously surrounded by computers and smart technologies (Cascio and Montealegre 2016) that perceive the environment and are able to react to it (Worden et al. 2003).

As Parker et al. (2017) pointed out, there is neither a direct positive nor a direct negative effect of technology on work design. Instead, the concrete effect of technology on aspects of work design (such as autonomy or relational aspects) is related to decisions made by relevant stakeholders in the design, introduction and use of technology in the organizational context (Rammert 2016; Waschull et al. 2020; Williams and Edge 1996). Therefore, changes in work design can be assumed for the future of production work (Parker and Grote 2020). However, to ensure that technologies are developed and applied in a desired direction, it is essential to gain deeper insights in these technologicaldriven changes and thus, to better understand the potential effects and interactions with work design, especially in the setting of production work. For this reason, a future-oriented Delphi-based study was conducted to scientifically derive possible developments in production work when implementing smart wearables.

\section{Literature review}

There is a large body of research on the relevance of technology in the work context (e.g. Orlikowski and Scott 2008; Ulich 1993), the adoption and diffusion of technology (e.g. Rogers 2003), and the relevance of technology for work design (e.g. Parker and Grote 2020; Wang et al. 2020). However, given the increasing prevalence of smart technologies (e.g. wearables like smart glasses) in the production envi- ronment, there is a lack of future scenarios that identify possible development paths for industrial work. In the following section, we will discuss the role of technology in the work context, presenting existing research findings on the relationship between smart technologies and work design.

\subsection{Work design and smart technologies}

Work design can broadly be defined as "choices made about the nature and content of people's jobs and how these choices affect individual and organizational outcomes" (Parker and Wall 2001, p. 90). Technology is seen as antecedent shaping different work characteristics and thereby influencing organizational, team- and individual outcomes, such as job performance, job satisfaction and employee well-being (e.g. Humphrey et al. 2007; Morgeson and Campion 2003; Parker 2003; Parker et al. 2001). Morgeson and Humphrey (2006) identified four key work characteristics. Task characteristics describe factors that influence the execution and accomplishment of the task (e.g. autonomy, task variety, feedback from job). Knowledge characteristics refer to the nature of knowledge, skills and abilities (e.g. breadth or specialization of knowledge) required of a person depending on the activity at work. Social characteristics refer to interpersonal aspects, interactions and cooperation at work, e.g. social support, interdependence and feedback from others. Finally, contextual characteristics describe the work environment and working conditions for employees, such as ergonomics and physical demands (Morgeson and Humphrey 2006; Stegmann et al. 2010).

Previous research on the impact of smart technology (e.g. information and communication technology; ICT) on the four core characteristics of work design revealed inconsistent results (e.g. Parker and Grote 2020; Wang et al. 2020). Looking at the impact of technology on task characteristics, it is noticeable that changes in autonomy are frequently studied (Wang et al. 2020). The use of ICT can have a positive impact on the perceived autonomy of employees (Moore et al. 2018; Wegman et al. 2018). If knowledge and relevant information is available to employees through ICT, this can also contribute to an increase in decision-making autonomy (Cascio and Montealegre 2016). Furthermore, these technologies enable an increased work scheduling autonomy regarding the decision on where and when to work (Johnson et al. 2020) and help employees to integrate requirements from different areas of life (Hill et al. 2001). On the other hand, this increased time- and location-independent working can also lead to an increased expectation of constant connectivity and the perceived need 
of employees for supplemental work. This fact might have a negative impact on the boundaries between work and personal live (e.g. Fenner and Renn 2010; Johnson et al. 2020) and therefore might reduce the perceived autonomy. The use of these technologies also enables greater monitoring and control of employees and the work process, which reduces autonomy (Cascio and Montealegre 2016; Fréour et al. 2021; Gerten et al. 2018).

Turning to implications of technology on knowledge characteristics, some researchers note that the increasing use of technologies leads to increased qualification requirements and skill variety (Pfeiffer 2018a; Wegman et al. 2018). This can be explained as increasing digitalization and automation leads to more complex processes. In order to be able to fix faults in such complex systems, employees need specialized knowledge (Fréour et al. 2021; Pfeiffer 2018a). In addition, smart technologies can provide relevant information to employees, enabling learning on the job, accomplishing more complex and diverse tasks, or greater participation in problem-solving processes (Blumberg and Kauffeld 2020; Szalavetz 2021). There are also risks for knowledge characteristics at work (Blumberg and Kauffeld 2020), such as simplification of work activities, which might result in a reduction of the variety of requirements or de-skilling (Kunst 2019; Szalavetz 2021).

Although social characteristics have long been studied less intensive than task and knowledge characteristics, the importance of interpersonal relationships in the workplace is undisputed (Grant and Parker 2009). ICT enables new ways of communication and access to knowledge. Therefore, it could be assumed for production work that the use of ICT might lead to new forms of work organization (e.g. a strengthening of teamwork; Bayo-Moriones et al. 2015). Studies have shown that ICT-mediated communication focusses mainly on task-related aspects and less on social or relational aspects. This could lead to a reduced perception of social support and therefore result in perceptions of loneliness, isolation and low satisfaction with work process (Barnes 2012; Monzani et al. 2014). However, virtual teams, most of which communicate through ICT technologies, can reach over time similar levels of interpersonal interaction and effectiveness as face-to-face teams (Rhoads 2010; Wilson et al. 2006).

Finally, Johnson et al. (2020) found in their literature review on technology-driven changes both positive and negative effects of technology use on contextual characteristics. Automation and smart technologies can increase job safety and support good health practices, which reflect positive contextual characteristics. Also, Ackerman and Kanfer (2020) point out, that the changing nature of work reduces physiological job demands. On the other hand, negative aspects of technology for the working environment, such as increased screen time and an increase in sedentary activ- ities, which can contribute to deterioration of ergonomics are found (Johnson et al. 2020).

The presented findings suggest that different aspects at the organizational (e.g. organizational support; Day et al. 2012) and individual level (e.g. individual skills; Wang et al. 2020) interplay with the characteristics and concrete applications of the technologies (e.g. information vs. communication technologies; Bloom et al. 2014) and can have both positive and negative effects on work performance, job satisfaction and well-being (e.g. Karimikia et al. 2020). Further, the data collection and usage as well as privacy concerns are particularly important and a critical factor in the introduction, acceptance and use of such technologies (Cascio and Montealegre 2016; Dhagarra et al. 2020; Fernandez 2014; Jacobs et al. 2019; Moore et al. 2018; Niknejad et al. 2020; Spagnolli et al. 2014). Restrictively, it must be taken into account that a large part of the study results relates to knowledge work and not to industrial work. This may also be due to the fact that smart technologies (e.g. smart wearables) are still in a design and deployment phase in industrial work and have hardly been studied in the operational application (Dey et al. 2018; Evers et al. 2018; Niknejad et al. 2020).

\subsection{Smart wearables in industrial work}

Smart wearables are one example of smart technologies and are a visible key element of the new quality of digitalization in the industrial work (Evers et al. 2018). They are defined as sensory electronic or mobile digital devices worn closely to the body; e.g. smart glasses or smartwatches. They assist employees in performing their jobs by presenting relevant information (Fernandez 2014; Niehaus 2017). In industrial production and logistics, there are various use cases for smart wearables, for example in assembly or logistics as well as in training, maintenance and quality assurance (Egger and Masood 2020). Although smart wearables are very widespread in the leisure and consumer sectors, smart glasses, for example, have hardly been used in the production sector to date (Syberfeldt et al. 2017). It is therefore not surprising that many studies have been conducted in laboratory environments (Niknejad et al. 2020). Experimental studies have found inconclusive results for workload (Funk et al. 2016; Gross et al. 2018; Kim et al. 2019), task completion time (Funk et al. 2016; Kim et al. 2019), and error rate (Funk et al. 2016; Kim et al. 2019) when using smart wearables compared to other work supports (e.g., paper-based). However, due to the experimental character of those previous studies, the impact of smart wearables on work design is neglected.

As mentioned above, the concrete application and design of technology can influence work design to varying degrees (Bloom et al. 2014; Wang et al. 2020). Therefore, it is im- 
portant to distinguish different applications of smart wearables. Facing this research gap, a recent interview study (Blumberg and Kauffeld 2020) examined smart wearables and mobile smart devices in industrial work and identified nine different categories of their application: communication (application for communication within and outside the team e.g. by voice, text or videos), identification (application for identification or registration at workplaces), management (application for the collection, analysis and evaluation of process data), navigation (application for navigation), occupational safety and health (application for the protection of employees from harmful stresses and hazards), coordination (application to support process and coordinative activities), competence development (application to support learning and teaching processes), quality assurance (application to ensure the quality of products and processes), and work task support (application to help employees in performing their work tasks). Although this classification of applications gives a first impression of how smart wearables can be used in industrial production, there is currently a lack of evidence on how work in production will actually change with an increased use of smart wearables. The question arises as to which development directions for work design will occur with different applications of smart wearables and how the work of production employees will change as a result.

\subsection{Research questions}

To facilitate the process of the digitalization of work and to actively shape changes due to digitalization in a way that successfully unfold its potential, it is important to gain deeper knowledge of future scenarios for industrial work with increased use of smart wearables. These scenarios and their evaluations help to make strategic decisions in the introduction and use of wearables. Therefore, we apply a three-stage Delphi-based survey to answer the following research questions:

RQ1 Which dimensions should be used to describe scenarios for the future of production work with increased use of smart wearables?

RQ2 Based on these dimensions: What scenarios can be derived for the future of production work with the increasing use of smart wearables?

RQ3 How is the desirability and the estimated probability of different scenarios for the future of production work with increased use of smart wearables evaluated?

RQ4 What are the key criteria for assessing the scenarios?

\section{Methodology}

In the following section, we will first introduce the Delphi method as an instrument for evaluating future developments under conditions of incomplete or nonexistent knowledge for a given issue (Häder 2009; Ono and Wedemeyer 1994; Profillidis and Botzoris 2019). We will then present the research process and the sample.

\subsection{Introduction to the Delphi method}

The research process of Delphi studies can best be described as an asynchronous group communication process (Linstone and Turoff 2011) consisting of "a series of intensive questionnaires interspersed with controlled opinion feedback" (Dalkey and Helmer 1963, p. 458).

The four key characteristics of the Delphi method include anonymity, iteration, controlled feedback and statistical aggregation of group response (von der Gracht 2012; Rowe et al. 1991; Rowe and Wright 2001). Anonymity of experts enables them to express their opinions freely and at the same time prevents negative group processes, such as peer pressure. Iteration describes that Delphi studies are conducted in a series of successive rounds (Rowe and Wright 2001). Controlled feedback provides the experts with information about how other participants have assessed and rated the items. This enables the participants to question their own assessment and change their opinion if necessary (Dalkey and Helmer 1963; Ono and Wedemeyer 1994). Typically, statistical summaries of the group responses (mean or median) are presented (Rowe and Wright 2001). Statistical aggregation of group response means that the estimation of the statements is reported as a group judgment. It allows a quantitative analysis of the judgements and the interpretation of the data (von der Gracht 2012). The Delphi procedure leads to a highly structured or controlled communication process among the experts and is intended to generate a more reliable assessment of future developments than can be achieved by individuals or interacting groups (Rowe and Wright 1999).

\subsection{Research process}

After a preparation phase, we conducted a three-round Delphi study followed by an additional post-evaluation workshop (cf. Fig. 1).

In the preparation phase, we conducted a literature review on the topics of work design, smart wearables and the interaction of work and technology. The findings resulted in the identification of relevant topics for the subsequent interviews (1st Delphi-round), which included the following topics: 


\begin{tabular}{|c|c|c|c|c|}
\hline & \multicolumn{3}{|c|}{3 round Delphi-study } & \multirow{4}{*}{$\begin{array}{l}\text { Post-evaluation workshop } \\
\text { Procedure } \\
\text { - remote workshop } \\
(03 / 2021) \\
\text { - } 6 \text { participants from a } \\
\text { manufacturing company } \\
\text { Outcome } \\
\text { - Review of the final } \\
\text { assessments and } \\
\text { discussion of the reasons } \\
\text { for each assessment }\end{array}$} \\
\hline Preparation phase & $1^{\text {st }}$ round (qualitative) & $2^{\text {nd }}$ round (quantitative) & $3^{\text {rd }}$ round (quantitative) & \\
\hline $\begin{array}{l}\text { Procedure } \\
\text { - Literature review } \\
\text { - Developing interview } \\
\text { questions }\end{array}$ & $\begin{array}{l}\text { Procedure } \\
\text { - } 76 \text { semi-structured face-to- } \\
\text { face interviews } \\
\text { - Qualitative data analysis } \\
\text { (Steigleder, 2008) }\end{array}$ & $\begin{array}{l}\text { Procedure } \\
\text { - Online-survey ( } 3 \text { weeks; } \\
08 / 2020-09 / 2020) \\
\text {. } 155 \text { participants from a } \\
\text { manufacturing company }\end{array}$ & $\begin{array}{l}\text { Procedure } \\
\text { - Online-survey ( } 3 \text { weeks; } \\
10 / 2020-11 / 2020 \text { ) incl. } \\
\text { Feedback } \\
\text { - } 133 \text { participants from a } \\
\text { manufacturing company }\end{array}$ & \\
\hline $\begin{array}{l}\text { Outcome } \\
\text { - Semi-structured interview } \\
\text { protocol }\end{array}$ & $\begin{array}{l}\text { Outcome } \\
\text { - Codes and categories } \\
\text { - Description dimensions } \\
\text { - Formulated scenarios }\end{array}$ & $\begin{array}{l}\text { Outcome } \\
\text { - First Assessment of the } \\
\text { scenarios regarding } \\
\text { desirability (7-point Likert } \\
\text { Scale) and probability } \\
\text { (percentage: } 0-100 \% \text { ) }\end{array}$ & $\begin{array}{l}\text { Outcome } \\
\text { - Final Assessment of the } \\
\text { scenarios regarding } \\
\text { desirability (7-point Likert } \\
\text { Scale) and probability } \\
\text { (percentage: } 0-100 \% \text { ) }\end{array}$ & \\
\hline \multicolumn{5}{|c|}{4} \\
\hline
\end{tabular}

Fig. 1 Research process

Abb. 1 Forschungsprozess

- Possible applications: How could smart wearables be applied in industrial work (focusing on assembly and logistics)?

- Work tasks: How will tasks and job content change for employees in assembly and logistics with increased use of smart wearables?

- Cooperation and leadership: How will collaboration and leadership change as smart wearables become increasingly used in assembly and logistics?

- Competencies and qualification: Which competencies are particularly important in assembly and logistics when smart wearables are increasingly used? How are employees qualified?

- Opportunities and Risks: What opportunities and risks arise for industrial work and employees when smart wearables are increasingly used?

The aim of this 1st round was to create future scenarios for industrial work in 2025 under the condition of an increased use of smart wearables. Scenarios can be defined as easily understandable, brief descriptions of a hypothetical but possible future state for a particular topic (HirschKreinsen 2017). For the development of scenarios, different characteristics of influencing or driving factors are combined (Gausemeier et al. 1998; Nakićenović et al. 2000). Therefore, scenarios often include various issues and are more complex than a single questionnaire item.

The aim of the 2nd Delphi-round was the quantitative assessment of the created scenarios. For this purpose, an online survey was conducted at a manufacturing company which in the following is refered to as "the organization". In the online survey the 18 identified scenarios (see Fig. 3) were evaluated in terms of desirability and probability. The desirability (D) of each scenario was assessed on an ordinal 7-point scale with adjective-anchored ends and mid $(1=$ not desired at all, $4=$ neutral, $7=$ very desirable). The probability (PE) was estimated in percentages from $0-100 \%$. The participants were asked to rate the current diffusion in the industrial environment and the probability of each scenario for the years 2025 and 2035. To reassess the scenarios in the $3 r d$ Delphi-round, we used the same questionnaire as in the 2 nd round (18 scenarios), but the participants received additional information on how the different scenarios were previously assessed. For this purpose, the mean value was given as a measure of the central tendency.

Finally, a post-evaluation workshop was conducted to understand which reasons were significant for the participants in assessing the scenarios in terms of their desirability and assumed probability. For this purpose, scenarios were selected based on the desirability ratings (highest and lowest), the assumed probability for 2025 and 2035 (highest and lowest) and the least consensus achieved. The participants of the workshop had already taken part in the two previous Delphi-rounds and were therefore familiar with the scenarios. In the workshop, participants were asked to describe and discuss with each other their reasons for assessing the scenarios.

\subsection{Samples}

Considering that the design and application of technology is shaped by social and communicational processes with different actors (Rammert 2016; Waschull et al. 2020; Williams and Edge 1996), we first identified relevant expert groups that influence the introduction and use of smart wearables in an organizational context. Following the expert selection procedure described by Okoli and Pawlowski (2004), we identified five expert groups: external to the organization: (1) researchers, (2) political actors (e.g. Federal Ministry, Labor unions), internal to the organization: 
Table 1 Sample description for 1st Delphi-round

Tab. 1 Stichprobenbeschreibung für die 1. Delphi-Runde

\begin{tabular}{|c|c|c|c|c|c|c|c|}
\hline \multicolumn{2}{|c|}{$\begin{array}{l}\text { Demographic vari- } \\
\text { ables }\end{array}$} & \multirow{2}{*}{$\begin{array}{l}\text { Researchers } \\
(n=16)\end{array}$} & \multirow{2}{*}{$\begin{array}{l}\text { Political actors } \\
(n=14)\end{array}$} & \multirow{2}{*}{$\begin{array}{l}\text { Planners and decision } \\
\text { makers } \\
(n=17)\end{array}$} & \multirow{2}{*}{$\begin{array}{l}\text { Workers coun- } \\
\text { cil } \\
(n=14) \\
-\end{array}$} & \multirow{2}{*}{$\begin{array}{l}\text { Industrial work- } \\
\text { ers } \\
(n=15) \\
6\end{array}$} & \multirow{2}{*}{$\begin{array}{l}\text { Total } \\
(n=76)\end{array}$} \\
\hline Age & $21-30$ & & & & & & \\
\hline (in & $31-40$ & 2 & 4 & 5 & 1 & 7 & 19 \\
\hline & $41-50$ & 4 & 4 & 4 & 6 & - & 18 \\
\hline & $51-60$ & 5 & 3 & 1 & 6 & 2 & 17 \\
\hline & $>60$ & 3 & 1 & - & - & - & 4 \\
\hline \multirow{5}{*}{$\begin{array}{l}\text { Work } \\
\text { experi- } \\
\text { ence } \\
\text { (in } \\
\text { years) }\end{array}$} & $0-4$ & 1 & - & 6 & - & - & 7 \\
\hline & $5-9$ & - & 3 & 2 & 1 & 4 & 10 \\
\hline & $10-14$ & 3 & 3 & 2 & - & 3 & 11 \\
\hline & $15-19$ & 2 & - & 3 & - & 5 & 10 \\
\hline & $>19$ & 10 & 8 & 4 & 12 & 3 & 37 \\
\hline
\end{tabular}

One person did not provide information on age and work experience

(3) planners and decision makers, (4) workers council, and (5) industrial workers who could use the devices in the future. The influence of these expert groups on the design and use of smart wearables in industrial production can be manifold (see Blumberg and Kauffeld 2020). The identification and acquisition of the participating experts was carried out, for example, by reviewing publications and research reports, lists of participants in internal company committees and described responsibilities within the company.

In the 1st Delphi-round 76 semi-structured face-to-face interviews with experts from the five expert groups were conducted. The interviews in this round were conducted with participants internal (working in the organization) as well as external to the organization. Hereby, the 46 participants of the three intra-company groups were from the same organization in which the 2nd and 3rd Delphi-round were conducted. The residual 30 interviews were conducted with political actors and researchers external to the organization. The demographic variables recorded were age and work experience (see Table 1).

To evaluate the future scenarios, we conducted two online surveys at the organization. The organization is a large international company in the automotive industry. In order to identify relevant participants for the survey within the company, we used the previously identified internal expert groups (planner and decision makers, workers council, industrial workers). The inclusion of these different groups should ensure heterogeneity in terms of demographic char- acteristics and professional experience. Participant diversity is an important factor in conducting Delphi studies and contributes to the variability of panelists' perspectives (Förster and von der Gracht 2014; Hussler et al. 2011). Experience with smart wearables were low to medium and showed also some variance indicating heterogeneity concerning experiences (2nd Delphi-round: $\mathrm{M}=2.6, \mathrm{SD}=1.15$ and 3rd Delphi-round: $\mathrm{M}=2.5, \mathrm{SD}=1.1$, rated on a 5-point scale with $1=$ no experience at all and $5=\mathrm{a}$ lot of experience). Due to internal organizational requirements, it was not possible to match participants' responses from round 2 and round 3 and no demographic variables other than age distribution could be collected (see Table 2). Participants (i.e., people who started to fill out the survey) and final sample (i.e., people fully assessed and rated all scenarios) for both Delphirounds are presented in Table 2.

In the post-evaluation workshop, six people from the manufacturing company participated. When selecting the participants, care was taken to ensure a heterogeneous composition of the group. The group consisted of equal numbers of men $(n=3)$ and women $(n=3)$. All participants had points of contact with production due to their occupation or worked in production at least some of the time. Three participants also had extensive experience in the field of digitization (e.g. AR or VR applications in the production environment or technology introduction process).

Table 2 Sample description for 2nd and 3rd Delphi-round

Tab. 2 Stichprobenbeschreibung für die 2. und 3. Delphi-Runde

\begin{tabular}{llllllll}
\hline $\begin{array}{l}\text { Delphi- } \\
\text { round }\end{array}$ & Participants & $\begin{array}{l}\text { Final } \\
\text { sample }\end{array}$ & \multicolumn{4}{l}{ Age distribution (absolute and percentage frequencies) } \\
\cline { 5 - 8 } & & & <25 years & 26-35 years & $36-45$ years & 46-55 years & $56-65$ years \\
\hline Round 2 & 155 & 121 & $7(4 \%)$ & $35(23 \%)$ & $46(30 \%)$ & $46(30 \%)$ & $18(12 \%)$ \\
Round 3 & 133 & 107 & $2(2 \%)$ & $28(22 \%)$ & $33(25 \%)$ & $47(36 \%)$ & $20(15 \%)$ \\
\hline
\end{tabular}




\section{Results}

\subsection{Description dimensions for future scenarios}

To answer RQ1 we integrated insights from the literature review as well as from the 76 interviews, which were transcribed (Dresing and Pehl 2015) and content-analyzed (Steigleder 2008). As a result, we identified six dimensions which are relevant to describe future scenarios:

1. Application of smart wearables: The concrete application of smart wearables in the production area is a relevant starting point to describe possible changes for production work. Building on Blumberg and Kauffeld's (2020) work, we use eight categories to describe possible applications of smart wearables: communication, identification, management, occupational safety and health, coordination, competence development, quality assurance and work task support.

2. Work design implications: Adopted from the work design framework (Morgeson and Campion 2003) and the work design questionnaire (Morgeson and Humphrey 2006; Stegmann et al. 2010), we distinguished between task characteristics, knowledge characteristics, social characteristics, and contextual characteristics to describe implications for work design.

3. Personalization: In the interviews, the respondents highlighted the possibilities of personalizing smart wearables, which makes a decisive difference to previous technologies in production. For the description of this personalization, we used Tossell et al.'s (2012) definition, which states that personalization describes the adaptation of a system to the requirements, needs and wishes of the user. This adaptation can either be self-directed by the user or adaptive web- or computer-based.
4. Flexibilization: Flexibilization describes the transition of work that encompasses time, place, functions, roles, competencies as well as social relationships and affects both the employee and the entire organization (Widuckel 2015). Thus, flexibility refers to the way in which work is organized (Kratzer et al. 2003).

5. Data usage: During the interviews, the experts' opinions differed as to whether smart wearables only provide predefined information or are also used as sensors to collect and analyze data. The relevance of data and privacy in the use of smart wearables has already been demonstrated in other studies (Moore et al. 2018; Niknejad et al. 2020). Therefore, the Data Use category describes different levels of data provision (see Fig. 2). These levels summarize existing considerations on different uses of data (Jeske et al. 2018; Kramer 2017). The provision of data and the collection of data were largely perceived by respondents as rather non-critical. This was different for the analysis of data and the transfer or further use of collected or generated data, which was seen as rather critical.

6. Organizational purpose: In the interviews, participants described different purposes for which smart wearables are introduced in companies. The purposes described were broadly in line with Pfeiffer's (2018b) distinction. She summarizes the central functions of the mechanization of work in three aspects: labor saving (e.g. reduction of manual tasks, automation), increase effectiveness (e.g. saving time) and process control (e.g. ensuring quality of the work process).

Concerning RQ1 we were able to identify six dimensions from the literature and the interviews conducted for the development and description of future scenarios. These dimensions and their characteristics are used in the following to describe possible changes in production work when using smart wearables from a work design perspective.

\begin{tabular}{|l|l|}
\hline \multicolumn{1}{|c|}{ Non-critical } \\
\hline \multicolumn{1}{|c|}{ Data provision } & \multicolumn{1}{|c|}{ Data collection } \\
\begin{tabular}{|l|} 
Smart wearables provide \\
relevant data for \\
employees \\
(e.g. learning nuggets, \\
information about the work \\
task).
\end{tabular} & $\begin{array}{l}\text { Smart wearables collect } \\
\text { and document data from } \\
\text { the environment (e.g. } \\
\text { process data, vital data). }\end{array}$ \\
\hline
\end{tabular}

\begin{tabular}{|l|l|}
\hline \multicolumn{1}{|c|}{ Critical } \\
\hline \multicolumn{1}{|c|}{ Data analysis } & \multicolumn{1}{|c|}{ Data sharing } \\
\begin{tabular}{|l|} 
Smart wearables analyze \\
data and, on request, \\
provide evaluations (e.g. \\
statistics on production \\
quality). The analysis can \\
be both general and \\
individual.
\end{tabular} & $\begin{array}{l}\text { Smart wearables transmit } \\
\text { captured data to others } \\
\text { within the organization. } \\
\text { The data can be both } \\
\text { anonymous and person- } \\
\text { specific. }\end{array}$ \\
\hline
\end{tabular}

Automated data aquistion and processing

Initiated human-machine interaction

Fig. 2 Levels of data usage by smart wearables

Abb. 2 Übersicht zu Level der Datennutzung durch Smart Wearables 


\subsection{Scenarios for the future of production work with the increasing use of smart wearables}

RQ2 dealt with the question what scenarios can be derived for the future of production work with the increasing use of smart wearables. To develop the scenarios, descriptions from the interviews and the identified six dimensions were used, resulting in 65 possible scenarios on the future of production work. These initial scenarios were summarized in several steps, revised and discussed with experts. Based on the nominal frequency of individual scenarios in the interviews, the novelty perceived by the experts, and the focus on changes for production employees, 18 scenarios (see Fig. 3) were developed, which can be described using the six previously identified criteria. Table 3 shows which characteristics of the six description dimensions identified in RQ1 are relevant in each scenario. To facilitate the understanding of these information, Fig. 4 presents scenario \#1
Fig. 3 Complete description of the scenarios incl. descriptive analysis of desirability and probability of implementation. ( $D$ Desirability, EP Estimated Probability. IQR $\leq 20$ indicates consensus)

Abb. 3 Komplette Beschreibung der Szenarien inklusive der descriptiven Beschreibungen zur Erwünschtheit und angenommenen Verbreitung ( $D$ Erwünschtheit, $E P$ angenommene Verbreitung. IQR $\leq 20$ indiziert einen Konsens bei der Bewertung durch die Experten)

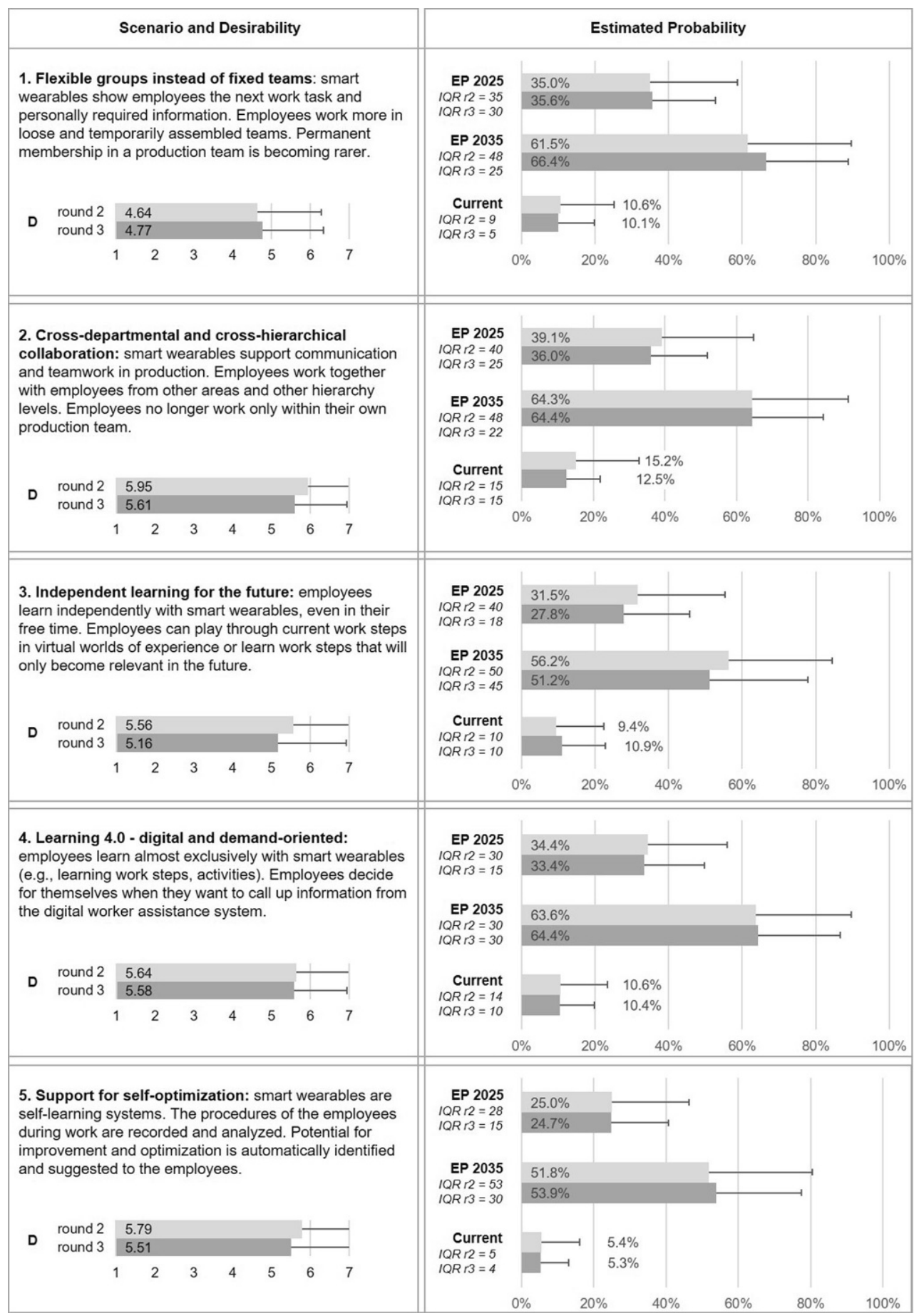


Fig. 3 (continued)

Abb. 3 (Fortsetzung)

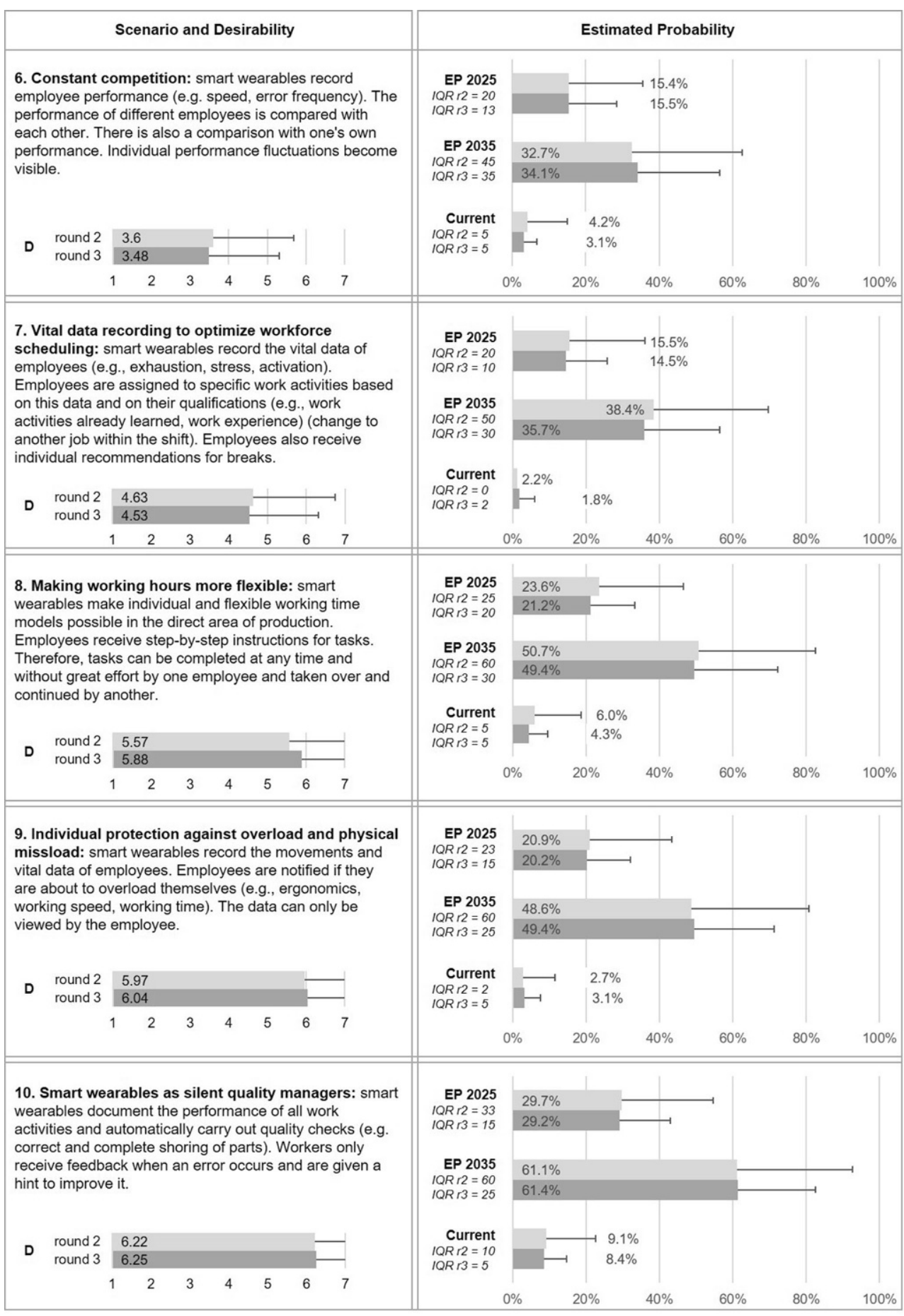

as an example. With these 18 scenarios, we have concisely described possible developments in production work in the use of smart wearables. In this way, the scenarios contribute to a better understanding of what changes could be expected for work organization and work design in operational practice if more smart wearables were to be used in the future.

\subsection{Desirability and estimated probability of the Delphi scenarios in 2025 and 2035}

To obtain insights into the desirability and assumed probability of the changes in production work described in the scenarios (RQ3), two quantitative Delphi-rounds were conducted. 
Fig. 3 (continued)

Abb. 3 (Fortsetzung)

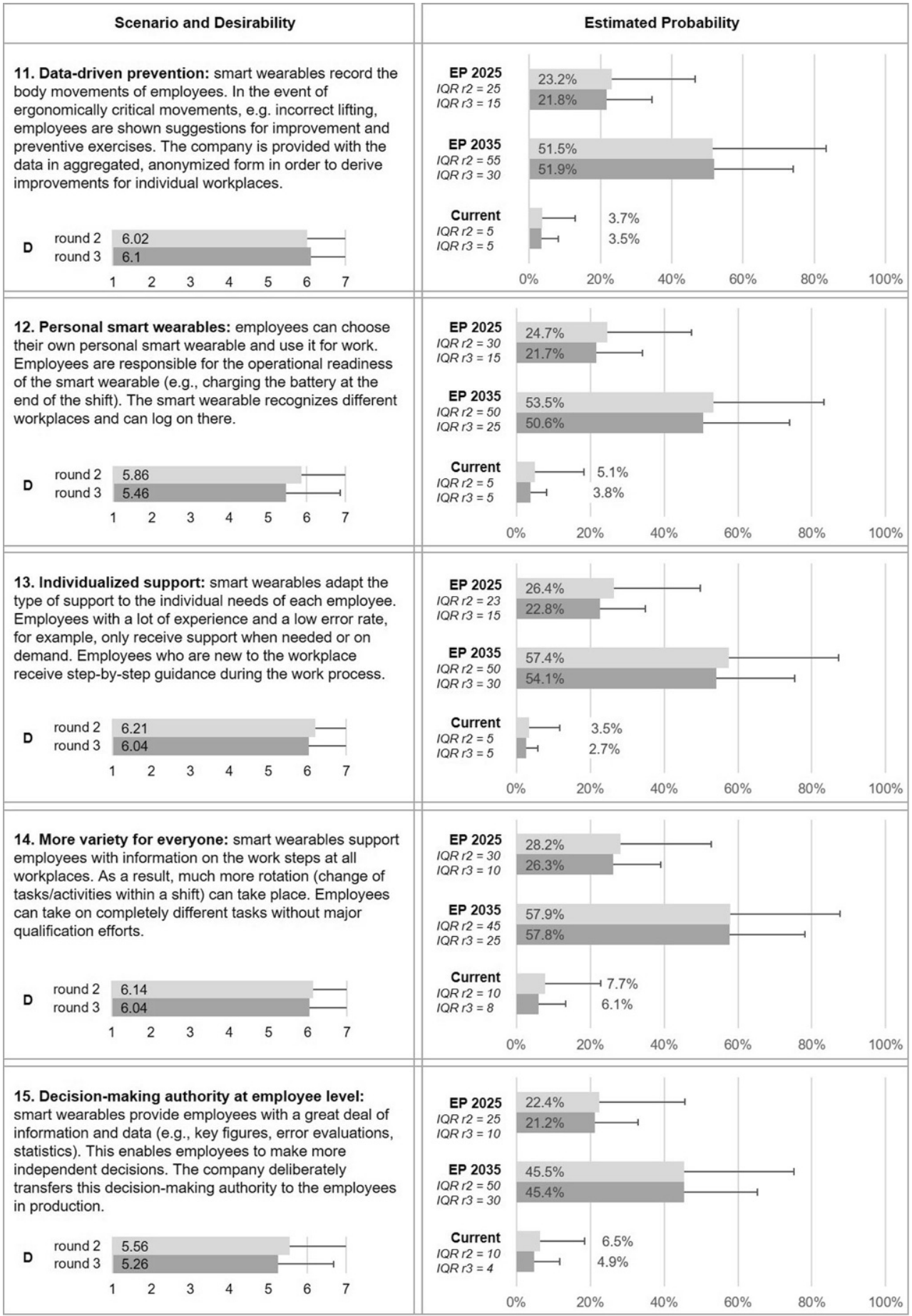

Statistics for the scenarios with respect to expert assessments of the desirability and probability of the scenarios in 2025 and 2035, as well as an estimate of current diffusion, are shown in Fig. 3. It also illustrates the interquartile range (IQR), as an indicator for the level of agreement between the experts. The IQR is the absolute difference of values between the third quartile and first quartile. Thus, the IQR contains the middle $50 \%$ of the responses. Smaller values of IQR indicate a higher level of consensus among the experts (von der Gracht 2012; Rayens and Hahn 2000; Scheibe et al. 2002). Consensus can be assumed if IQR is no larger than 2 units on a 10-unit scale (Scheibe et al. $2002)$, i.e. on a 100 -unit scale (0-100\%) for all scenarios with an IQR $\leq 20$ (Bokrantz et al. 2017). In the following, we first give an example for the interpretation of the results 
Fig. 3 (continued)

Abb. 3 (Fortsetzung)

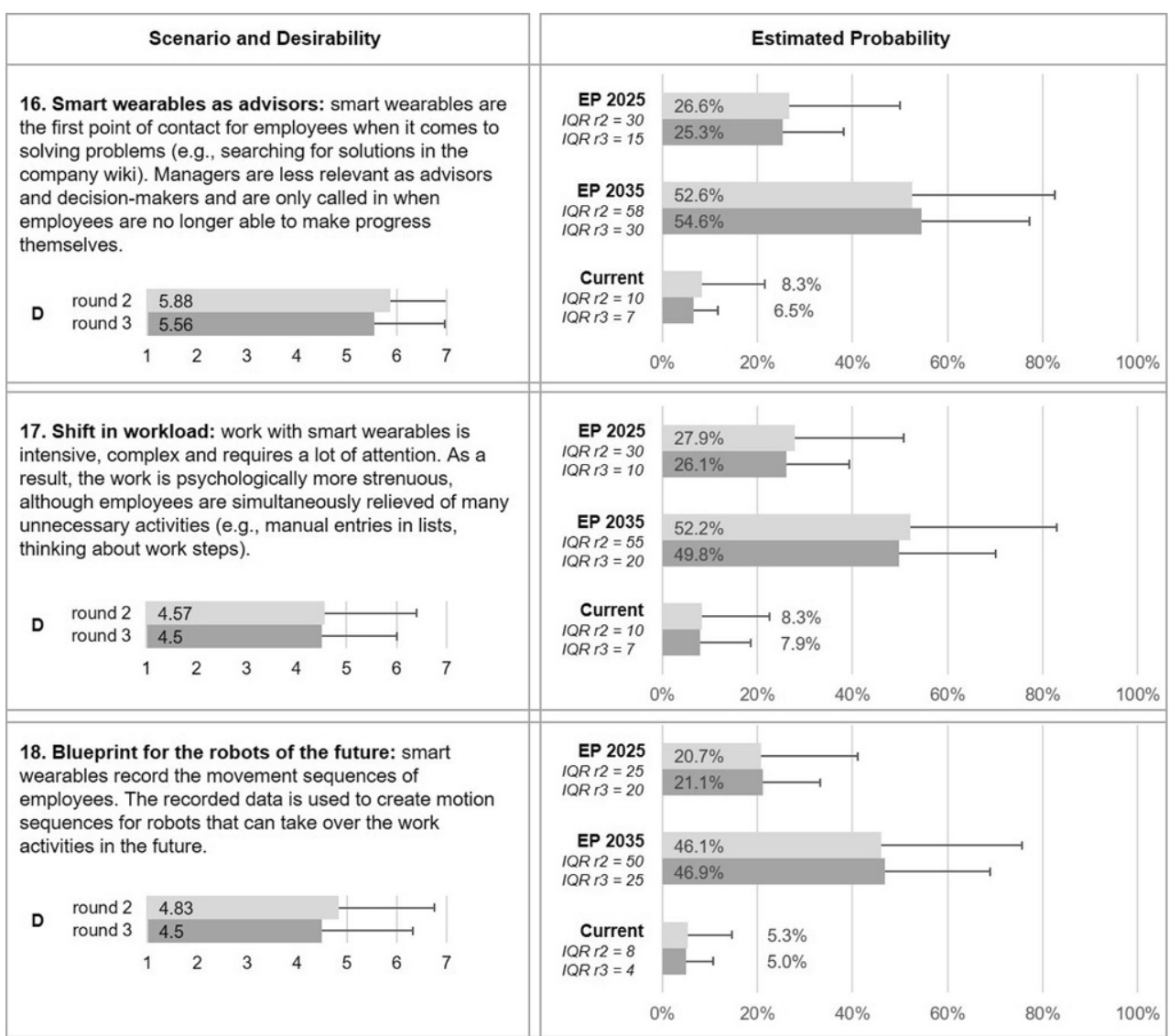

for each scenario, followed by a summary of the results for both Delphi-rounds.

\subsubsection{Scenario \# 1 "Flexible groups instead of fixed teams": An example}

To facilitate the scenario specific interpretation (see Fig. 3), we introduce scenario \#1 as an example: The desirability for this scenario was evaluated with 4.64 in the 2nd and 4.77 in the 3rd round. Referring back to the 7-point response scale, in which the value 4 was anchored with the adjective "neutral", the scenario is viewed rather neutrally to slightly positive. The mean probability for year 2025 was evaluated with $35 \%$ in the 2 nd and $36 \%$ in the 3 rd round, i.e. there is only a slight mean change between the two rounds. Thus, the implementation of the scenario by 2025 is assumed to be rather unlikely (Bañuls and Turoff 2011). For year 2035 the mean probability was evaluated with $62 \%$ in round two and $66 \%$ in round three, showing that the implementation in 2035 is assumed to be likely (Bañuls and Turoff 2011). For both years, the standard deviation (SD) decreased from the 2 nd to the 3 rd round (2025: from 24 to 17; 2035: from 28 to 23). This could indicate that the experts adjusted their assessments and moved closer to the group opinion as a re- sult of the controlled feedback from the results of the 2 nd Delphi-round.

The IQR value, which indicates a consensus between the experts' assessments, decreases for scenario \#1 from the 2nd to the 3rd Delphi-round for the estimated degree of dissemination of the scenario for the years 2025 and 2035 (2025: 2nd round: $I Q R=35 ; 3$ rd round: $I Q R=30 ; 2035$ : 2nd round: $I Q R=48 ; 3$ rd round: $I Q R=25$ ). This shows that the experts have become more similar in their assessments. However, both values are above the cut-off value of 20 , which means that no consensus among the experts could be reached in the assessment of the diffusion of the scenario. Finally, the estimates for the future probabilities of this scenario can be compared with the evaluated current estimates. The mean value and the standard deviation of the current state of diffusion slightly decreased (2nd round: $M=11 \%$, $\mathrm{SD}=15 ;$ 3rd round: $\mathrm{M}=10 \%, \mathrm{SD}=10$ ). In both rounds $\mathrm{IQR}$ was $\leq 20$ (2nd round: $\mathrm{IQR}=9$; 3rd round: $\mathrm{IQR}=5$ ) indicating a high level of agreement among experts on the current degree of diffusion. In summary, it can be stated for scenario \#1 that the scenario is considered as rather desirable and the current spread in operational practice as highly improbable (Bañuls and Turoff 2011). With regard to the future spread of this scenario, experts assume that this scenario will only be found in a few places in operational prac- 
Table 3 Assignment of the scenarios to the classification categories

Tab. 3 Zuordnung der Szenarien zu den Klassifikationskriterien

\begin{tabular}{|c|c|c|c|c|c|c|}
\hline No. & Appl. & Work design & Pers. & Flex. & Data usage & Purpose \\
\hline 1 & $\begin{array}{l}\text { WTS, } \\
\text { MNG }\end{array}$ & SC: Social support $\downarrow$ & $\mathrm{x}$ & $\mathrm{x}$ & Provision & Effectiveness \\
\hline 2 & $\mathrm{CO}$ & SC: Social support $\uparrow$ & - & - & - & Effectiveness \\
\hline 3 & QUAL & TC: Autonomy $\uparrow$ & - & $\mathrm{x}$ & Provision & Effectiveness \\
\hline 4 & QUAL & $\begin{array}{l}\text { TC: Autonomy } \uparrow, \text { SC: Social sup- } \\
\text { port } \downarrow\end{array}$ & - & - & Provision & Effectiveness \\
\hline 5 & $\begin{array}{l}\text { MNG, } \\
\text { WTS }\end{array}$ & TC: Autonomy $\downarrow$ & - & - & Collection, analysis & $\begin{array}{l}\text { Effectiveness, process } \\
\text { control }\end{array}$ \\
\hline 6 & MNG, QA & SC: Social support $\downarrow$ & - & - & $\begin{array}{l}\text { Collection, analysis, shar- } \\
\text { ing }\end{array}$ & Effectiveness \\
\hline 7 & $\begin{array}{l}\text { OSH, } \\
\text { ORG }\end{array}$ & CC: Ergonomics $\uparrow$ & $\mathrm{x}$ & - & $\begin{array}{l}\text { Provision, collection, } \\
\text { analysis }\end{array}$ & Effectiveness \\
\hline 8 & $\begin{array}{l}\text { WTS, } \\
\text { (ORG) }\end{array}$ & TC: Autonomy $\uparrow$, Complexity $\downarrow$ & - & $\mathrm{x}$ & Provision & Process control \\
\hline 9 & $\mathrm{OSH}$ & CC: Ergonomics $\uparrow$ & $\mathrm{x}$ & - & Collection, analysis & Process control \\
\hline 10 & QA, WTS & TC: Feedback $\uparrow$ & - & - & Collection, analysis & Process control \\
\hline 11 & $\begin{array}{l}\text { OSH, } \\
\text { MNG }\end{array}$ & CC: Ergonomics $\uparrow$ & - & - & $\begin{array}{l}\text { Collection, analysis, shar- } \\
\text { ing }\end{array}$ & Process control \\
\hline 12 & ID & CC: Equipment use $\uparrow$ & $\mathrm{x}$ & - & Collection & - \\
\hline 13 & WTS & TC: Feedback $\uparrow$ & $\mathrm{x}$ & - & $\begin{array}{l}\text { Provision, collection, } \\
\text { analysis }\end{array}$ & Process control \\
\hline 14 & $\begin{array}{l}\text { WTS, } \\
\text { QUAL }\end{array}$ & TC: Task variety $\uparrow$ & - & $\mathrm{x}$ & Provision & $\begin{array}{l}\text { Effectiveness, process } \\
\text { control }\end{array}$ \\
\hline 15 & MNG & KC: Problem solving $\uparrow$ & - & - & Provision & Effectiveness \\
\hline 16 & $\begin{array}{l}\text { ORG, } \\
\text { WTS }\end{array}$ & $\begin{array}{l}\text { KC: Problem solving } \uparrow, \text { SC: Social } \\
\text { support } \downarrow\end{array}$ & - & - & Provision & Effectiveness \\
\hline 17 & WTS & $\begin{array}{l}\text { KC: Job complexity } \uparrow, \text { CC: Physi- } \\
\text { cal demands } \downarrow\end{array}$ & - & - & Collection & Process control \\
\hline 18 & MNG & TC: Task significance $\downarrow$ & - & - & $\begin{array}{l}\text { Collection, analysis, shar- } \\
\text { ing }\end{array}$ & Labor saving \\
\hline
\end{tabular}

Appl. Application, Pers Personalization, Flex Flexibilization

Application (cf. Blumberg and Kauffeld 2020): $C O$ communication, $I D$ identification, $M N G$ (data) management, $O S H$ occupational safety and health, $O R G$ coordination, $Q U A L$ competence development, $Q A$ quality assurance, WTS work task support

Work design: SC Social characteristics, TC Task characteristics, $K C$ Knowledge characteristics, $C C$ Contextual characteristics

tice in 2025. In 2035, the occurrence of such a situation is assumed to be probable. It should be noted, however, that the experts' assessments vary and, as indicated by the high IQR values, no agreement was reached on the diffusion rate in 2025 and 2035 .

\subsubsection{Summary of quantitative results}

In addition to the detailed interpretation of scenario \#1, the overall examination of the results of both Delphi-rounds (cf. Fig. 3) revealed an average of the desirability of the scenarios of $\mathrm{M}=5.5$ in the 2 nd and $\mathrm{M}=5.3$ in the 3 rd round. As a mean value of 4 would be neutral, the values indicate rather desirable evaluations. Further, scenarios were assessed similarly across rounds (i.e. evaluated as particularly desirable or undesirable in both rounds). In terms of desirability, scenario \#10, which describes the use of smart wearables for quality assurance, was considered the most desirable (2nd round: $M=6.2$, 3rd round: $M=6.3$ ) and scenario \#6, which describes the use of smart wearables for performance measurement and comparison, the most undesirable (2nd round: $\mathrm{M}=3.6$, 3rd round: $\mathrm{M}=3.5$ ).

The current state of the scenarios was evaluated as very improbable with $\mathrm{M}=6.9 \%$ in the $2 \mathrm{nd}$ and $\mathrm{M}=6.1 \%$ in the 3 rd round. This can be an indicator that the future scenarios described here can hardly be found in operational practice so far. The assumed probability for the year 2025 of the scenarios was $M=26.1 \%$ in the 2 nd and $M=24 \%$ in the 3 rd round. This shows that overall the implementation of the scenarios in operational practice by 2025 is considered improbable. The highest prevalence in 2025 was assumed in both rounds for scenario \#2 (Cross-departmental and cross-hierarchical collaboration; 2 nd round: $\mathrm{M}=39.1 \%$; 3 rd round: $\mathrm{M}=36 \%$ ). The lowest prevalence for 2025 was assumed in the 2nd round for scenario \#6 (constant competition; 2nd round: $\mathrm{M}=15.4 \%$; 3 rd round: $\mathrm{M}=15.5 \%$ ) 
Fig. 4 Detailed overview of the assigned classification categories for scenario \#1: Flexible groups instead of fixed teams Abb. 4 Detaillierter Überblick der zugeordneten Klassifikationskriterien für Szenario \#1: Flexible Gruppen statt feste Teams

\begin{tabular}{|c|l|}
\hline Application & $\begin{array}{l}\text { Displaying the work task as well as additional information is assigned to the application category "work task } \\
\text { support" (WTS). Using smart wearables to assign the employee to a specific task corresponds to the } \\
\text { application category "management" (MNG). }\end{array}$ \\
\hline Work design & $\begin{array}{l}\text { Permanent membership in a production team is becoming rarer. This can be accompanied by negative } \\
\text { consequences for the social workplace characteristics, as the sense of belonging and social support could } \\
\text { decrease. }\end{array}$ \\
\hline Personalization & Required information are presented, which means that the system adapts to the requirements of the user. \\
\hline Flexibilization & $\begin{array}{l}\text { Loose and temporarily assembled teams: Through flexible assignments to tasks, fixed team structures } \\
\text { become rarer. }\end{array}$ \\
\hline Data usage & $\begin{array}{l}\text { Smart wearables make the necessary data available, i.e., they display it. The display or provision of } \\
\text { information corresponds to non-critical data use (cf. Fig. 2). }\end{array}$ \\
\hline Purpose & \begin{tabular}{l} 
The main purpose is to increase effectiveness. \\
\hline
\end{tabular} \\
\hline
\end{tabular}

and in the 3rd round for scenario \#7 (Vital data recording to optimize workforce scheduling 2nd round: $\mathrm{M}=15.5 \%$; 3rd round: $\mathrm{M}=14.5 \%$ ). The assumed probability for the year 2035 of the scenarios was $M=52.5 \%$ in the 2 nd and $\mathrm{M}=52.3 \%$ in the $3 \mathrm{rd}$ round. The highest prevalence in 2035 was assumed in the 2 nd round for scenario \#2 (Cross-departmental and cross-hierarchical collaboration; 2nd round: $M=64.3 \%$; 3 rd round: $M=64.4 \%$ ) and in the $3 \mathrm{rd}$ round for scenario \#1 (Flexible groups instead of fixed teams; 2nd round: $M=61.5 \%$; 3rd round: $M=66.4 \%$ ). The results show that the participants consider it likely that these two scenarios will be implemented in operational practice by 2035. The lowest prevalence for 2035 was assumed in both rounds for scenario \#6 (constant competition; 2nd round: $M=32.7 \%$; 3rd round: $M=34.1 \%$ ). The values show that the implementation of this scenario in operational practice in 2035 is considered unlikely.

With regard to RQ3, it was shown that 17 of the 18 scenarios developed were considered rather desirable. Furthermore, it was found that for the year 2025, a diffusion of 16 of the 18 scenarios in operational practice is estimated to be highly unlikely to rather unlikely. For the year 2035, the existence of the scenarios in operational practice is considered unknown to probable (Bañuls and Turoff 2011) for 16 out of 18 scenarios.

\subsection{Scatter plots of the evaluation of the scenarios for 2025 and 2035}

To deepen the understanding of the distribution of the 18 estimated scenarios, a scatter plot was created. Fig. 5a presents the evaluated probabilities of scenarios for the year 2025 from the final Delphi-round as a function of indicated desirability. It can be seen that for the year 2025 a rather low degree of dissemination is assumed for all scenarios. This is noticeable, as the scenarios were developed based on the changes in industrial work described in the interviews for the year 2025 (see 1st round: expert interviews). Nevertheless, in the following rounds, the participants rated the probability of occurrence in industrial practice for the year 2025 as low. For the 16 scenarios within the dashed lines, a high level of agreement on the estimated probability among the experts was reached (IQR $\leq 20$ ). For the two scenarios that were considered most likely in 2025, no consensus could be reached between the participants' assessments. This concerned scenario \#1 (flexible groups instead of fixed teams; 2nd round: $I Q R=35$, 3rd round: $\mathrm{IQR}=30$ ) as well as scenario \#2 (cross-departmental and cross-hierarchical collaboration; 2nd round: $\mathrm{IQR}=40$, 3rd round: $\mathrm{IQR}=25$ ).

Fig. $5 \mathrm{~b}$ presents the estimated probabilities of the scenarios for the year 2035. The scenarios are predominantly estimated to have a moderate degree of dissemination. The highest probabilities were assumed for scenario \#1, scenario \#2, and scenario \#4 (learning 4.0-digital and demand oriented). However, contrary to the results for 2025 , a high level of agreement in the expert assessments could only be achieved for scenario \#17 (shift in workload; 2nd round: $\mathrm{IQR}=55,3 \mathrm{rd}$ round: $\mathrm{IQR}=30$ ), for which a prevalence of $49.8 \%$ was assumed. For all other scenarios, IQR was $>20$, indicating no consensus among participants. Opinions on the degree of diffusion of the scenario \#3 (Independent learning for the future; 2 nd round: $I Q R=50,3 \mathrm{rd}$ round: $\mathrm{IQR}=45$ ) and scenario \#6 (constant competition; 2nd round: $I Q R=45$, 3rd round: $I Q R=35$ ) differed particularly strongly. As Schmalz et al. (2021) point out, it is beneficial not only to focus on the scenarios for which consensus has been reached, but also to take a closer look at the scenarios where there is the greatest disagreement among experts, i.e. the scenarios with the highest IQR. The high IQR may reflect a high level of uncertainty (Schmalz et al. 2021). 
Fig. 5 Desirability-probability scatter plot of scenarios a for the year 2025 (3rd round); $\mathbf{b}$ for the year 2035 (3rd round)

Abb. 5 Erwünschtheits-Verbreitungs-Scatterplot für die Scenarien a im Jahr 2025; b im Jahr 2035 (Die dargestellten Daten entsprechen den Daten aus der dritten Delphi-Runde)
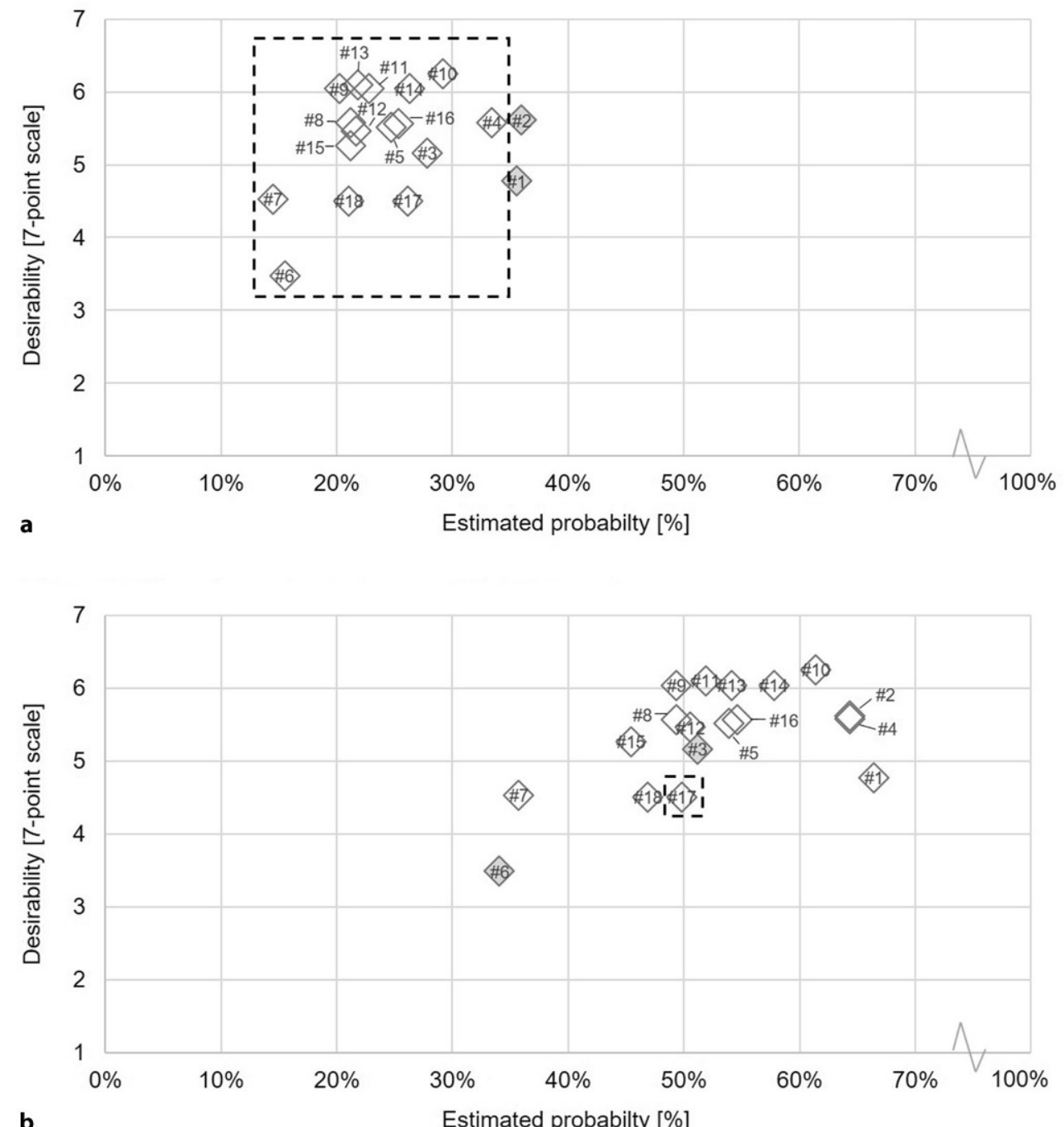

The graphical representation quickly shows that the participants largely agree on their assessment of a rather low level of diffusion for the scenarios in 2025, indicated by low IQR-values. With regard to the dissemination of scenarios in 2035, it becomes clear that a diffusion of the scenarios is seen in a much more differentiated way and that a consensus could only be reached for the evaluation of one scenario (\#17). This shows that participants are less in agreement on a long-term assessment of the degree of diffusion.

\subsection{Further analysis: data use and perceived privacy}

To gain a further understanding of the scenario assessments, we divided the scenarios into critical and non-critical in terms of the type of data use (see Fig. 2). Previous studies were able to show that data usage as well as perceived privacy impact the intention to use certain technology (Dhagarra et al. 2020; Jacobs et al. 2019; Spagnolli et al. 2014). We therefore assigned all scenarios in which the provision and collection of data were described to the non-critical cluster (e.g. \#1 flexible groups instead of fixed teams, \#3 independent learning for the future, \#14 more variety for everyone). Scenarios that described smart wearables evaluating data or making further use of data were assigned to the critical cluster (e.g. \#6 constant competition, \#10 smart wearables as silent quality managers, \#11 datadriven prevention). A paired-samples t-test was performed to detect mean differences between the scenarios classified as non-critical and critical. Results are shown in Table 4. No significant mean differences were found at either time point related to the desirability of the critical and non-critical scenarios (2nd round: $\mathrm{t}(120)=1.44, p=0.154 ; \mathrm{d}=0.13$; 3rd round: $\mathrm{t}(106)=-0.096, p=0.923 ; \mathrm{d}=0.01)$. However, significant differences were found between the critical and non-critical scenarios in terms of their estimated probability in 2025 (2nd round: $\mathrm{t}(120)=7.980, p<0.001 ; \mathrm{d}=0.73$; 3rd round: $\mathrm{t}(106)=9.516, p<0.001 ; \mathrm{d}=0.92)$ and 2035 (2nd round: $\mathrm{t}(120)=5.582, p<0.001 ; \mathrm{d}=0.51$; 3rd round: 
Table 4 Mean comparisons of the critical and non-critical clustered scenarios

Tab. 4 Mittelwertsvergleiche für kritisch und nicht-kritisch eingeschätzte Szenarien

\begin{tabular}{|c|c|c|c|c|c|c|c|}
\hline & \multicolumn{2}{|c|}{ Non-critical data usage } & \multicolumn{2}{|c|}{ Critical data usage } & \multicolumn{2}{|l|}{ t-test } & \multirow{2}{*}{$\begin{array}{l}\text { Cohen's d } \\
\text { d }\end{array}$} \\
\hline & $\overline{\mathrm{M}}$ & SD & $\bar{M}$ & SD & $\mathrm{T}$ & $p \leq$ & \\
\hline \multicolumn{8}{|c|}{$2 n d$ round $(n=121)$} \\
\hline $\mathrm{D}$ & 5.52 & 0.88 & 5.41 & 1.06 & 1.435 & 0.154 & 0.13 \\
\hline EP2025 & 28.25 & 18.36 & 22.09 & 18.32 & 7.980 & 0.001 & 0.73 \\
\hline EP2035 & 54.85 & 21.83 & 48.44 & 23.94 & 5.582 & 0.001 & 0.51 \\
\hline \multicolumn{8}{|c|}{$3 r d$ round $(n=107)$} \\
\hline $\mathrm{D}$ & 5.31 & 0.88 & 5.33 & 0.98 & -0.096 & 0.923 & 0.01 \\
\hline EP2025 & 26.43 & 10.32 & 21.19 & 10.27 & 9.516 & 0.001 & 0.92 \\
\hline EP2035 & 54.06 & 17.20 & 48.18 & 17.91 & 7.124 & 0.001 & 0.69 \\
\hline
\end{tabular}

$D$ Desirability, EP Estimated Probability

$\mathrm{t}(106)=7.124, p<0.001 ; \mathrm{d}=0.69)$. The effect sizes for the estimated probabilities indicate medium to large effects (Cohen 1988). Thus, also there is no significant difference in the assessment of desirability between critical and noncritical scenarios, there is a significant difference in the estimated probability, the way that non-critical scenarios are considered more likely.

\subsection{Key criteria for the evaluation of the scenarios}

In order to answer RQ4 and identify key criteria that guided the evaluation of the scenarios, a post-evaluation workshop was conducted. Seven scenarios (\#3, \#6, \#10, \#11, $\# 1$, \#2, \#7) were selected based on high or low desirability ratings, high or low assumed probability for 2025 and 2035 and the least consensus achieved, i.e. indicated by high IQR-values (cf. Figs. 3 and 5). Due to time constraints, four scenarios were prioritized and discussed in depth by the participants. Table 5 presents the scenarios as well as the identified key criteria for the evaluation of the scenarios.

The discussion in the post-evaluation workshop gives first hints that different aspects were relevant for the participants in the assessment of the scenarios in terms of desirability and degree of realization. The implications of the scenarios for work design were cited by the participants as a significant factor for all four scenarios discussed. It can be seen that the effects on work design can be assessed both as conducive (e.g., more feedback, scenario \#10) to the assessment of the scenario and as a hindrance (e.g. reduced autonomy and a blurring of work and leisure, scenario \#3). Economic aspects were also identified as a relevant key criterion for the assessment of the scenarios for all four scenarios discussed. The aspect of costs was critically discussed, especially in terms of investment costs (scenario \#3). At the same time, the participants emphasized positive economic expectations when using smart wearables, for example to increase quality and efficiency (scenario \#10, \#6). The fit to the corporate culture and strategy as well as the technical feasibility were named for three scenarios as deci- sion-guiding aspects for their assessment. Furthermore, the handling of data described in the scenario was considered when assessing the scenarios. Based on the post-evaluation workshop, we were able to identify five relevant key factors (work design, economic aspects, corporate culture and strategy, technical feasibility and data handling) that were particularly relevant for the participants when assessing the scenarios.

\section{Discussion}

The aim of this Delphi-based study was to describe possible changes in production work with the increasing use of smart wearables and to derive implications for work design. We have therefore first identified description dimensions for the development of future scenarios (RQ1), resulting in six core dimensions (application, implications for work design, personalization, flexibilization, data usage and purpose, see Table 3). 18 Scenarios for the future of production work were derived from expert interviews (RQ2, see Fig. 3). They formed the starting point for a deeper examination and analysis. In two quantitative Delphi-rounds the scenarios were evaluated in terms of their desirability and the estimated probability in 2025 and 2035 (RQ3, see Fig. 3). With a post-evaluation workshop, key criteria, i.e. work design, economic aspects, corporate culture and strategy, data handling, and technical feasibility could be identified that were relevant for the participants in the evaluation of the scenarios (RQ4, see Table 5).

In terms of the assessment of the scenarios, 17 out of 18 scenarios were considered rather desirable (see Fig. 5). Scenarios describing the use of smart wearables to monitor work quality (\#10 Smart wearables as silent quality managers) and improve ergonomics (\#11 Data-driven prevention, \#9 Individual protection against overload and physical missload) were rated as most desirable. This shows that when using smart wearables, improvements for employees and the quality of the product are considered desirable. Sce- 
Table 5 Identified key criteria for the assessment of selected scenarios in the post-evaluation workshop

Tab. 5 Identifizierte Kernkriterien für die Einschätzung ausgewählter Szenarien im Post-Evaluation-Workshop

\begin{tabular}{lll}
\hline Inclusion & Identified key criteria & \\
\cline { 2 - 3 } Criteria $^{\text {a }}$ & Supporting the scenario & Contradicting the scenario \\
\hline
\end{tabular}

Scenario \#3 Independent learning for the future

IQREP2035 $\uparrow \quad$ Corporate culture and strategy: development and learning as corporate values

Importance of lifelong learning: continuing training is becoming increasingly relevant and the trend towards lifelong learning is continuing

Work design-Autonomy: flexibility regarding learning time and place

Economic aspects: device provision and availability associated with acquisition costs

Technical feasibility: lack of data availability to provide virtual experience worlds

Work design-Autonomy: increased merging of work and private life

\section{Scenario \#6 Constant competition}

EP $2035 \downarrow, \quad$ Economic aspects: increased effectiveness

$\mathrm{D} \downarrow$

Individual level characteristics/needs: satisfies the need for feedback, self-optimization, and competitive demands

Corporate culture and strategy: scenario odds with the values of the company

Work design: competition can be perceived as control that leads to more stress and performance pressure

\section{Scenario \#10 Smart wearables as silent quality managers}

D $\uparrow \quad$ Technical feasibility: similar approaches already exist today (e.g. pick-by-light, automated quality-check)

Data handling: data collection refers to quality/product not to the employee

Economic aspects: e.g. training time reduction, increase in efficiency

Corporate culture and strategy: scenario fits with strategy and goals

Work design: direct and neutrally convoyed feedback

\section{Scenario \#11 Data-driven prevention}

$\mathrm{D} \uparrow \quad$ Technical feasibility: some approaches already exist today Work design: improvement of physically demanding workplaces

Data handling: a lot of data has to be collected, evaluated and personalized

Economic aspects: avoidance of health-related staff shortages

Data handling: aggregation and anonymization of data before disclosure

${ }^{a}$ Explanation on the inclusion criteria: $Q R_{E P 2035} \uparrow$ highest IQR-value in the assessment of the estimated probability in 2035 (3rd round $\mathrm{IQR}=45$ ), indicates a high disagreement between the participants in the assessment of the scenario, $D \downarrow$ low desirability, $D \uparrow$ high desirability, EP $2035 \downarrow$ lowest estimated probability in 2035

nario \#6 (constant competition) is the only scenario that was considered rather undesirable. Already today, performance in production is transparent, e.g., due to tracking of quantities and error rates, but usually only at team level. Continuous individual tracking (e.g. Baethge et al. 2017) and a conscious comparison of performance could further intensify the perceived performance and time pressure and reduce well-being (e.g. Sonnentag et al. 2010) and was therefore considered undesirable. This concern was also expressed in the post-evaluation workshop (see Table 5). Time pressure is particularly negative, if the time specifications are considered to be obstructive or unrealistic (Lepine et al. 2005).

The assumed prevalence of the scenarios in 2025 was estimated to be low. For 16 out of 18 scenarios, a consensus was reached on this assessment, which is a strong indicator that the described scenarios will hardly be found in industrial practice by 2025 . This result is surprising because the interviews that formed the basis for the development of the scenarios asked about changes in production work up to
2025. One reason for the difference between the scenarios derived from the interviews for 2025 and the final assessment of implementation of the scenarios in practice in 2025 could be the t-focused bias of the experts surveyed in the interview phase (Linstone and Turoff 2011). The t-focused bias describes that engineers and scientists in particular tend to overestimate the short-term implementation of existing technological possibilities. Obstacles such as organizational conditions or non-technical difficulties are overlooked (Linstone and Turoff 2011). Scientists and political actors who were involved in the interview phase may have had the current state of development of the technologies and possibilities for their application in mind when considering the future scenarios. Operational practitioners may have based their assessments of the scenarios in the 2nd and 3rd rounds more strongly on their experiences with the implementation process and feasibility within a company. This is also suggested by the results of the post-evaluation workshop (see Fig. 1). The participants indicated that the technical feasi- 
bility and corporate culture and strategy were key criteria in assessing the scenarios (RQ4, see Table 5).

While the spread of the scenarios in 2025 was considered to be unlikely, the participants assumed a moderate prevalence of 16 of the 18 scenarios for 2035 . However, it must be noted that a consensus on estimated probability could only be reached among the experts for one single scenario in 2035 (\#17 shift in workload). This indicates a huge uncertainty regarding the assessment of implementation probabilities.

The highest level of diffusion for the year 2025 was assumed for scenario \#2 (cross-departmental and cross-hierarchical collaboration) and scenario \#1 (flexible groups instead of fixed teams). Both scenarios describe possible changes in collaboration in the sense of an expansion (\#2) or dissolution (\#1) of the team structures established in industrial production today (Schlick et al. 2018). Nevertheless, it should be noted that there was no agreement in the assessment of these two scenarios. The results show that the use of smart wearables makes new forms of collaboration and cooperation in production work possible, but that the concrete implementation in operational practice is subject to great uncertainty.

A subsequent analysis of the scenarios showed that the assumed probability, but not the desirability, of scenarios was related to the forms of data usage described in the scenarios (non-critical vs. critical, see Fig. 2). This supports existing findings that have shown that the issue of data usage and privacy concerns are relevant to the dissemination and use of these new technologies (Dhagarra et al. 2020; Jacobs et al. 2019; Spagnolli et al. 2014). The fact that critical scenarios and non-critical scenarios do not differ in terms of desirability could be due to the fact that the more automatic evaluation and use of data results in additional advantages in use. For example, adaptation to user needs (cf. \#13 individualized support) is only possible if user-specific data is collected, evaluated and combined with performance data (e.g., error rates). In terms of probability, critical scenarios are assumed to be less likely than non-critical scenarios. It can be assumed that a critical use of data (see Fig. 2) and the associated risks are recognized and due to applicable legal regulations (e.g. GDPR) the dissemination is assumed to be less likely. This is also supported by the results of the post-evaluation workshop, in which the handling of data was identified as a relevant key criterion for the evaluation of the scenarios. When smart wearables are used, transparency should be created about the collection and use of data. Furthermore, data protection fears should be taken very seriously. At the same time, however, it should also be critically examined whether concerns about data protection violations are preventing the introduction of desired technologies or making it unnecessarily difficult.

\subsection{Implications}

Our study contributes to research on technology implementation and work design in the increasing use of smart wearables in operational practice. The scenarios developed are a valuable contribution to research and practice and can provide relevant insights into possible developments of production work and work design as the use of smart wearables increases. The specific consideration of a single technology enables a comprehensive view of conceivable changes.

In work design frameworks (e.g. Morgeson and Campion 2003) and current work design studies (e.g. Parker and Grote 2020), technologies are included as a relevant factor. Our study results suggest that in addition to the technology and its application, the topic of data use can also be a relevant aspect to describe changes in work design (RQ1) and to explain the degree of dissemination (RQ4, further analysis) of new technologies in the work context. Future studies should therefore include data usage in order to explore the influence of different data uses on work design and relevant outcomes. The distinction between critical and non-critical data uses (see Fig. 2) can provide a starting point for this.

In addition, the scenarios, in the development of which the perspectives of different relevant expert groups were included, describe possible development directions for the production work. In the following, we would like to show which implications arise from the different scenarios for the four core characteristics of work design as well as for data use.

With regard to task characteristics it should be noted, that in industrial production, both work methods autonomy and work scheduling autonomy are often low due to the standardized description of procedures, processes and work steps of lean production (Lantz et al. 2015), as well as due to a commitment to shift models (e.g. Parker 2003). Smart wearables could increase the autonomy of production workers when used to support employees' decision-making autonomy, e.g. over their learning (\#3, \#4) and working time (\#8). Another way to improve task characteristics is to allow feedback on task performance to be displayed by the smart wearable (\#10,\#13). This gives employees direct and immediate feedback on their own work performance and enables them to better assess their own performance. In addition, employees can be supported in performing new or unfamiliar tasks through the use of smart wearables (e.g. by displaying necessary work steps, \#14) and thus increase task variety for employees. Care should be taken when smart wearables are used to further optimize workflows (\#18) and contribute to the further standardization of workflows by suggesting the most efficient processes (\#5).

Today, knowledge characteristics are supported in the context of production work through the use of group work, in which employees assume responsibility for the distribu- 
tion of tasks in the team, problem solving and quality assurance, among other things (Schlick et al. 2018). From the scenarios, further approaches for improving the knowledge characteristics can be derived. In this way, the provision of relevant data and evaluations on smart wearables can be used to enable employees to make an even greater contribution to problem solving (\#15,\#16). In order to design these possibilities in industrial practice, companies should consider how necessary process data can be collected, evaluated, visualized and made available in order to prepare a subsequent problem solution in the team in the best possible way. On the other hand, companies must ensure that the demands on employees do not lead to an excessive increase in job complexity (\#17) and should therefore support the necessary competence development with suitable qualification formats.

In terms of social characteristics, work teams form a central anchor point. Fixed team membership is common in the production sector today (Schlick et al. 2018). Two scenarios describe possible changes in these stable team relationships (\#1, \#2). Scenario \#1 describes a temporary, short-term composition of different employees in a group with unstable membership. Studies on the importance of social support in the work context showed that social support by colleagues, e.g. by providing help or sharing information, is a relevant job resource (Bakker and Demerouti 2007; Hobfoll 1989; Morgeson et al. 2013). In ad-hoc teams, the lack of personal knowledge and mental models could lead to a lower team cohesion (Bushe and Chu 2011). On the other hand, by breaking down team boundaries (\#1) and strengthening cross-divisional and cross-hierarchical cooperation (\#2), new networks could be built up in companies. Building on social network research, weak ties with many people may even be seen as an advantage compared to a permanent team membership, as they provide access to new and important information or act as a bridge between different communities (Granovetter 1983, 1973). In addition, Scenario \#6 describes the use of smart wearables for performance comparison in the team. This could have negative effects such as less mutual support.

Smart wearables can also be used to enhance contextual characteristics. Particularly in production work, which is still physically demanding in many places today, opportunities to improve ergonomics should be consistently exploited. Scenarios \#7, \#11, and \#9 provide some starting points for improving ergonomics through the use of smart wearables. From the description of the scenarios, it can be seen that by recording vital data (\#7, \#9) and movement data (\#9, \#11), smart wearables can provide information to improve ergonomics. Furthermore, care should be taken to ensure that the use of smart wearables does not result in a shift or additional mental stress, as described in scenario \#17. Companies should therefore pay particu- lar attention to user-friendly design when introducing smart wearables.

The mobile accessibility of data for all employees is a central advantage in the use of smart wearables. Many of the scenarios described can only be realized with this form of data provision. With regard to data use, companies should consciously weigh up which data needs to be collected, evaluated or further used. Particularly in the production sector, where a great deal of data is already being collected by machines, the use of smart wearables to collect additional data is creating challenges for data protection. Companies should consciously address these and create suitable solutions to prevent employees from becoming "transparent employees" through the use of smart wearables. The identified indications for the use of smart wearables in production areas with regard to work design and data use are independent of the size of the company and are therefore highly relevant for both large companies and SMEs.

\subsection{Limitations}

There are some limitations in this study that we would like to address below. First, methodologically, there are limitations due to the predefined number of Delphi-rounds. In the interview phase, experts from outside the company as well as members of a production company were involved. The subsequent quantitative survey took place within a company, so that a maximum of two rounds could be carried out. Although a pre-determined number of Delphi-rounds is reported in many Delphi studies (Diamond et al. 2014), this procedure contradicts the principle that Delphi studies are only completed when a high degree of stability in the assessment of the scenarios has been achieved (Rowe and Wright 2001). However, studies show that, repeated rounds of questioning can lead to fatigue in respondents and therefore a higher number of rounds can lead to a higher drop-out rate (Keeney et al. 2001; Rowe and Wright 2001). A second limitation results from the fact that the participant data from the 2nd and 3rd Delphi-rounds could not be matched and it was not possible for the participants to use free text fields to explain their scenario assessment. This limited certain evaluations (e.g. with regard to changes in the opinion of individual participants).

A third limitation arises with regard to the generalizability of the results. Different experts and perspectives were used to create the future scenarios both inside and outside the company. However, the subsequent assessment of the scenarios in terms of desirability and degree of dissemination was carried out within one company. Therefore, specifics of the company must be taken into account when interpreting the data. For example, the size, the organizational structure and the innovativeness of a company can have an impact on innovation adoption decisions (Dewett 
et al. 2007; Frambach and Schillewaert 2002). However, in order to obtain the broadest possible assessment of future developments and scenarios for a changed production work with the increasing use of smart wearables, expert groups inside and outside the company were included in the interview phase, which was the basis for the development of the scenarios. Furthermore, the information provided by the participants of the two quantitative rounds on experience with smart wearables showed that there is also a great deal of heterogeneity within the same company when it comes to exploring smart wearables. In addition, many different areas and target groups within the company were addressed for participation in the two quantitative Delphi-rounds, which should also ensure a great diversity in terms of knowledge and perspectives (Dougherty 1992; Tortoriello et al. 2012). However, future studies should focus more on the extent to which different companies and industries differ in the assessment and, above all, in the implementation of these new technologies in order to provide target group-specific starting points for the implementation and use of smart wearables.

\subsection{Conclusion}

This study shows how different application scenarios of smart wearables can influence the work design in production. The identified opportunities and risks make it clear that "work design matters more than ever in a digital world" (Parker and Grote 2020, p. 1). Companies should therefore be aware of the impact on the key characteristics of work design when introducing these technologies. In addition, a human-centered design of the technologies and the associated application scenarios should be carried out in order to support the successful introduction and use of the technologies. The new possibilities of smart wearables offer the opportunity not only to increase the efficiency of processes, but also to improve the work design in industrial production and shape it for the future.

Funding Open Access funding enabled and organized by Projekt DEAL.

Open Access This article is licensed under a Creative Commons Attribution 4.0 International License, which permits use, sharing, adaptation, distribution and reproduction in any medium or format, as long as you give appropriate credit to the original author(s) and the source, provide a link to the Creative Commons licence, and indicate if changes were made. The images or other third party material in this article are included in the article's Creative Commons licence, unless indicated otherwise in a credit line to the material. If material is not included in the article's Creative Commons licence and your intended use is not permitted by statutory regulation or exceeds the permitted use, you will need to obtain permission directly from the copyright holder. To view a copy of this licence, visit http://creativecommons.org/licenses/by/4. $0 /$.

\section{References}

Ackerman PL, Kanfer R (2020) Work in the 21st century: New directions for aging and adult development. Am Psychol 75(4):486-498. https://doi.org/10.1037/amp0000615

Baethge A, Vahle-Hinz T, Schulte-Braucks J, van Dick R (2017) A matter of time? Challenging and hindering effects of time pressure on work engagement. Work Stress 32(3):228-247. https://doi.org/ 10.1080/02678373.2017.1415998

Bakker AB, Demerouti E (2007) The job demands-resources model. State of the art. Journal of Managerial Psych 22(3):309-328. https://doi.org/10.1108/02683940710733115

Barnes S-A (2012) The differential impact of ICT on employees. Narratives from a hi-tech organisation. New Technol Work Employ 27(2):120-132. https://doi.org/10.1111/j.1468-005X.2012. 00283.x

Bayo-Moriones A, Billon M, Lera-López F (2015) Are new work practices applied together with ICT and AMT? Int J Hum Resour Manag 28(4):553-580. https://doi.org/10.1080/09585192.2015. 1116453

Bañuls VA, Turoff M (2011) Scenario construction via Delphi and cross-impact analysis. Technol Forecast Soc Change 78(9):1579_ 1602. https://doi.org/10.1016/j.techfore.2011.03.014

Bloom N, Garicano L, Sadun R, van Reenen J (2014) The distinct effects of information technology and communication technology on firm organization. Manage Sci 60(12):2859-2885. https://doi. org/10.1287/mnsc.2014.2013

Blumberg VSL, Kauffeld S (2020) Anwendungsszenarien und Technologiebewertung von digitalen Werkerassistenzsystemen in der Produktion - Ergebnisse einer Interview-Studie mit Experten aus der Wissenschaft, der Politik und der betrieblichen Praxis. Gr Interakt Org 51(1):5-24. https://doi.org/10.1007/s11612-02000506-0

Bokrantz J, Skoogh A, Berlin C, Stahre J (2017) Maintenance in digitalised manufacturing. Delphi-based scenarios for 2030. Int J Prod Econ 191:154-169. https://doi.org/10.1016/j.ijpe.2017.06.010

Bushe GR, Chu A (2011) Fluid teams. Organ Dyn 40(3):181-188. https://doi.org/10.1016/j.orgdyn.2011.04.005

Cascio WF, Montealegre R (2016) How technology is changing work and organizations. Annu Rev Organ Psychol Organ Behav 3(1):349-375. https://doi.org/10.1146/annurev-orgpsych041015-062352

Cohen J (1988) Statistical power analysis for the behavioral sciences, 2nd edn. Lawrence Erlbaum Associates; Taylor and Francis, New York

Dalkey N, Helmer O (1963) An experimental application of the Delphi method to the use of experts//an experimental application of the DELPHI method to the use of experts. Manage Sci 9(3):458-467. https://doi.org/10.1287/mnsc.9.3.458

Day A, Paquet S, Scott N, Hambley L (2012) Perceived information and communication technology (ICT) demands on employee outcomes: the moderating effect of organizational ICT support. J Occup Health Psychol 17(4):473-491. https://doi.org/10.1037/ a0029837

Dewett T, Whittier NC, Williams SD (2007) Internal diffusion. The conceptualizing innovation implementation. Compet Rev 17(1/2):8-25. https://doi.org/10.1108/10595420710816579

Dey A, Billinghurst M, Lindeman RW, Swan JE (2018) A systematic review of 10 years of augmented reality usability studies: 2005 to 2014. Front Robotics Ai 5:37. https://doi.org/10.3389/frobt.2018. 00037

Dhagarra D, Goswami M, Kumar G (2020) Impact of trust and privacy concerns on technology acceptance in healthcare: an Indian perspective. Med Inf 141:104164. https://doi.org/10.1016/j.ijmedinf. 2020.104164

Diamond IR, Grant RC, Feldman BM, Pencharz PB, Ling SC, Moore AM, Wales PW (2014) Defining consensus: a system- 
atic review recommends methodologic criteria for reporting of Delphi studies. J Clin Epidemiol 67(4):401-409. https://doi.org/ 10.1016/j.jclinepi.2013.12.002

Dougherty D (1992) Interpretive barriers to successful product innovation in large firms. Organ Sci 3(2):179-202. https://doi.org/10. 1287/orsc.3.2.179

Dresing T, Pehl T (2015) Praxisbuch Interview, Transkription \& Analyse. Anleitungen und Regelsysteme für qualitativ Forschende, 6th edn. Eigenverlag, Marburg (https://www.audiotranskription. de/Praxisbuch-Transkription.pdf, zuletzt geprüft am 28.12.2020.)

Egger J, Masood T (2020) Augmented reality in support of intelligent manufacturing-A systematic literature review. Comput Ind Eng 140(30):106195. https://doi.org/10.1016/j.cie.2019.106195

Evers M, Krzywdzinski M, Pfeiffer S (2018) Designing wearables for use in the workplace: the role of solution developers. WZB Berlin Social Science Center, Berlin

Fenner GH, Renn RW (2010) Technology-assisted supplemental work and work-to-family conflict. The role of instrumentality beliefs, organizational expectations and time management. Hum Relations 63(1):63-82. https://doi.org/10.1177/0018726709351064

Fernandez P (2014) Wearable technology. Beyond augmented reality. Libr Hi Tech News. https://doi.org/10.1108/LHTN-09-20140082

Förster B, Gracht, von der Heiko (2014) Assessing Delphi panel composition for strategic foresight-A comparison of panels based on company-internal and external participants. Technol Forecast Soc Change 84:215-229. https://doi.org/10.1016/j.techfore.2013. 07.012

Frambach RT, Schillewaert N (2002) Organizational innovation adoption. A multi-level framework of determinants and opportunities for future research. J Bus Res 55(2):163-176. https://doi.org/10. 1016/S0148-2963(00)00152-1

Fréour L, Pohl S, Battistelli A (2021) How digital technologies modify the work characteristics: a preliminary study. Span J Psychol. https://doi.org/10.1017/SJP.2021.12

Funk, Markus; Kosch, Thomas; Schmidt, Albrecht (2016): Interactive worker assistance: comparing the effects of in-situ projection, head-mounted displays, tablet, and paper instructions. In: Proceedings of the 2016 ACM International Joint Conference on Pervasive and Ubiquitous Computing. UbiComp '16: Proceedings of the 2016 ACM International Joint Conference on Pervasive and Ubiquitous Computing. Heidelberg Germany, 12.-16. September 2016. New York: Association for Computing Machinery, Pages 934-939.

Gausemeier J, Fink A, Schlake O (1998) Scenario management. Technol Forecast Soc Change 59(2):111-130. https://doi.org/10.1016/ S0040-1625(97)00166-2

Gerten E, Beckmann M, Bellmann L (2018) Controlling working crowds: the impact of digitalization on worker autonomy and monitoring across hierarchical levels. WWZ Working Pape, 2018/09. University of Basel, Center of Businessand Economics (WWZ), Basel

Gracht HA von der (2012) Consensus measurement in Delphi studies. Technol Forecast Soc Change 79(8):1525-1536. https://doi.org/ 10.1016/j.techfore.2012.04.013

Granovetter M (1983). The Strength of Weak Ties: A Network Theory Revisited. Sociological Theory 1:201-233. https://doi.org/10. 2307/202051

Granovetter MS (1973) The strength of weak ties. Am J Sociol 78(6): $1360-1380$

Grant AM, Parker SK (2009) 7 redesigning work design theories. The rise of relational and proactive perspectives. Acad Manag Ann 3(1):317-375. https://doi.org/10.1080/19416520903047327

Gross B, Bretschneider-Hagemes M, Stefan A, Rissler J (2018) Monitors vs. Smart glasses: a study on cognitive workload of digital information systems on forklift trucks. In: Duffy VG (ed) Digital human modeling. Applications in health, safety, ergonomics, and risk management 9th International Conference, DHM 2018, Held as Part of HCI International 2018, Las Vegas, July 15-20, 2018. Lecture Notes in Computer Science, 10917. Springer, Cham, pp 569-578 (Proceedings)

Häder M (2009) Delphi-Befragungen. Ein Arbeitsbuch, 2nd edn. VS, Wiesbaden

Hill EJ, Hawkins AJ, Ferris M, Weitzman M (2001) Finding an extra day a week: the positive influence of perceived job flexibility on work and family life balance. Fam Relat 50(1):49-58

Hirsch-Kreinsen H (2016) Digitization of industrial work. Development paths and prospects. J Labour Mark Res 49(1):S1-S14. https://doi.org/10.1007/s12651-016-0200-6

Hirsch-Kreinsen H (2017) Digitalisierung industrieller Einfacharbeit. Arbeit 26(1):9. https://doi.org/10.1515/arbeit-2017-0002

Hobfoll SE (1989) Conservation of resources. A new attempt at conceptualizing stress. Am Psychol 44(3):513-524

Humphrey SE, Nahrgang JD, Morgeson FP (2007) Integrating motivational, social, and contextual work design features: a meta-analytic summary and theoretical extension of the work design literature. J Appl Psychol 92(5):1332-1356. https://doi.org/10.1037/ 0021-9010.92.5.1332

Hussler C, Muller P, Rondé P (2011) Is diversity in Delphi panelist groups useful? Evidence from a French forecasting exercise on the future of nuclear energy. Technol Forecast Soc Change 78(9):1642-1653. https://doi.org/10.1016/j.techfore.2011.07.008

Jacobs JV, Hettinger LJ, Yueng-Hsiang H, Jeffries S, Lesch MF, Simmons LA et al (2019) Employee acceptance of wearable technology in the workplace. Appl Ergon 78:148-156. https://doi.org/10. 1016/j.apergo.2019.03.003

Jeske T, Weber M-A, Klues J, Lennings F (2018) Strukturierung und Analyse von Praxisbeispielen zur Nutzung der Digitalisierung für das Produktivitätsmanagement. Z Arb Wiss 72(3):190-199. https://doi.org/10.1007/s41449-018-0105-Z

Johnson A, Dey S, Nguyen H, Groth M, Joyce S, Tan L et al (2020) A review and agenda for examining how technology-driven changes at work will impact workplace mental health and employee wellbeing. Aust J Manag 45(3):402-424. https://doi.org/10.1177/ 0312896220922292

Karimikia H, Singh H, Joseph D (2020) Negative outcomes of ICT use at work. Meta-analytic evidence and the role of job autonomy. INTR 31(1):159-190. https://doi.org/10.1108/INTR-09-20190385

Keeney S, Hasson F, McKenna HP (2001) A critical review of the Delphi technique as a research methodology for nursing. Int J Nurs Stud 38:195-200

Kim S, Nussbaum MA, Gabbard JL (2019) Influences of augmented reality head-worn display type and user interface design on performance and usability in simulated warehouse order picking. Appl Ergon 74:186-193. https://doi.org/10.1016/j.apergo.2018.08.026

Kramer U (2017) Selbstbestimmter Umgang mit Gesundheits-Apps? Über welche Kompetenzen müssen Verbraucher_innen verfügen? Haushalt Bild Forsch 6(2):16-30. https://doi.org/10.3224/hibifo. v6i 2.02

Kratzer N, Sauer D, Hacket A, Trinks K, Wagner A (2003) Flexibilisierung und Subjektivierung von Arbeit. Institut für Sozialwissenschaftliche Forschung e.V. ISF München. München. https:// www.ssoar.info/ssoar/handle/document/23554. Accessed 4 Jan 2021

Kunst D (2019) Deskilling among manufacturing production workers. Tinbergen institute discussion paper. Tinbergen institute. Amsterdam and (TI 2019-050/VI). https://www.econstor.eu/bitstream/ 10419/205340/1/19050.pdf. Accessed 27 June 2021

Lantz A, Hansen N, Antoni C (2015) Participative work design in lean production. JWL 27(1):19-33. https://doi.org/10.1108/JWL-032014-0026

Lasi H, Fettke P, Kemper H-G, Feld T, Hoffmann M (2014) Industry 4.0. Bus Inf Syst Eng 6(4):239-242. https://doi.org/10.1007/ s12599-014-0334-4 
Lepine JA, Podsakoff NP, Lepine MA (2005) A meta-analytic test of the challenge stressor-hindrance stressor framework. An explanation for inconsistent relationships among stressors and performance. AMJ 48(5):764-775. https://doi.org/10.5465/AMJ.2005. 18803921

Linstone HA, Turoff M (2011) Delphi. A brief look backward and forward. Technol Forecast Soc Change 78(9):1712-1719. https://doi. org/10.1016/j.techfore.2010.09.011

Monzani L, Ripoll P, Peiró JM, van Dick R (2014) Loafing in the digital age. The role of computer mediated communication in the relation between perceived loafing and group affective outcomes. Comput Human Behav 33(1):279-285. https://doi.org/10.1016/j.chb.2014. 01.013

Moore P, Piwek L, Roper I (2018) The quantified workplace: a study in self-tracking, agility and change management. In: Btihaj Ajana (ed) Self-tracking. Springer, Cham, pp 93-110

Morgeson FP, Campion MA (2003) Work Design. In: Borman WC, Weiner IB (eds) Industrial and organizational psychology. Handbook of psychology, vol 12. Wiley, Hoboken, pp 423-452

Morgeson FP, Humphrey SE (2006) The Work Design Questionnaire (WDQ): developing and validating a comprehensive measure for assessing job design and the nature of work. J Appl Psychol 91(6):1321-1339. https://doi.org/10.1037/0021-9010.91.6.1321

Morgeson FP, Garza AS, Campion MA (2013) Work Design. In: Schmitt NW, Highhouse S (eds) Industrial and organizational psychology, 2nd edn. Handbook of psychology, vol 12. Wiley, Hoboken, pp 525-559

Nakićenović N, Alcamo J, Davis G, de Vries B, Fenhann J, Gaffin S et al (2000) Special report on emissions scenarios. A special report of working group III of the intergovernmental panel on climate change. Cambridge University Press, Cambridge

Niehaus J (2017) Mobile Assistenzsysteme für Industrie 4.0: Gestaltungsoptionen zwischen Autonomie und Kontrolle. FGW Forschungsinstitut für gesellschaftliche Weiterentwicklung (e. V.). https://d-nb.info/1175041157/34. Accessed 24 Jan 2021

Niknejad N, Waidah Binti I, Mardani A, Huchang L, Ghani I (2020) A comprehensive overview of smart wearables. The state of the art literature, recent advances, and future challenges. Eng Appl Artif Intell 90:103529. https://doi.org/10.1016/j.engappai.2020.103529

Okoli C, Pawlowski SD (2004) The Delphi method as a research tool. An example, design considerations and applications. Inf Manag 42(1):15-29. https://doi.org/10.1016/j.im.2003.11.002

Ono R, Wedemeyer DJ (1994) Assessing the validity of the Delphi technique. Futures 26(3):289-304. https://doi.org/10.1016/00163287(94)90016-7

Orlikowski WJ, Scott SV (2008) 10 Sociomateriality. Challenging the separation of technology, work and organization. Acad Manag Ann 2(1):433-474. https://doi.org/10.1080/19416520802211644

Parker SK (2003) Longitudinal effects of lean production on employee outcomes and the mediating role of work characteristics. J Appl Psychol 88(4):620-634. https://doi.org/10.1037/0021-9010.88.4. 620

Parker SK, Grote G (2020) Automation, algorithms, and beyond. Why work design matters more than ever in a digital world. Appl Psychol 8(1):101. https://doi.org/10.1111/apps.12241

Parker SK, Wall TD (2001) Work design: learning from the past and mapping a new terrain. In: Anderson N (ed) Personnel psychology. Handbook of industrial, work and organizational psychology, vol 1. SAGE, London, pp 90-109 (Reprint)

Parker SK, van den Broeck A, Holman D (2017) Work design influences. A synthesis of multilevel factors that affect the design of jobs. Annals 11(1):267-308. https://doi.org/10.5465/annals.2014. 0054

Parker SK, Wall TD, Cordery JL (2001) Future work design research and practice: towards an elaborated model of work design. J Occup Organ Psychol 74:413-440

Pfeiffer S (2018a) The 'future of employment' on the shop floor. Why production jobs are less susceptible to computerization than as- sumed. Int J Res Voc Educ Training 5(3):208-225. https://doi.org/ 10.13152/IJRVET.5.3.4

Pfeiffer S (2018b) Technisierung von Arbeit. In: Böhle Voß FGG, Wachtler G (eds) Arbeit, Strukturen und Prozesse, 2nd edn. Handbuch Arbeitssoziologie, vol 1. Springer, Wiesbaden, pp 321-357

Profillidis VA, Botzoris GN (2019) Modeling of transport demand. Analyzing, calculating, and forecasting transport demand. Elsevier, Amsterdam

Rammert W (2016) Technik - Handeln - Wissen. Zu einer pragmatistischen Technik- und Sozialtheorie, 2nd edn. Springer VS, Wiesbaden

Rayens MK, Hahn EJ (2000) Building consensus using the policy Delphi method. Policy Polit Nurs Pract 1(4):308-315

Rhoads M (2010) Face-to-face and computer-mediated communication. What does theory tell us and what have we learned so far? J Plan Lit 25(2):111-122. https://doi.org/10.1177/08854122103 82984

Rogers EM (2003) Diffusion of innovations, 5th edn. Free Press trade paperback edition. Free Press, New York, London, Toronto, Sydney

Rowe G, Wright G (1999) The Delphi technique as a forecasting tool. Issues and analysis. Int J Forecast 15(4):353-375. https://doi.org/ 10.1016/S0169-2070(99)00018-7

Rowe G, Wright G (2001) Expert opinions in forecasting: the role of the Delphi technique. In: Armstrong JS (ed) Principles of forecasting, vol 30. Springer US, Boston, pp 125-144

Rowe G, Wright G, Bolger F (1991) Delphi: a reevaluation of research and theory. Technol Forecast Soc Change 39(3):235-251. https:// doi.org/10.1016/0040-1625(91)90039-I

Scheibe M, Skutsch M, Schofer J (2002) Experiments in Delphi methodology. In: Linstone HA, Turoff M (eds) The Delphi method. Techniques and applications. Addison-Wesley, Reading, pp 257-281

Schlick C, Bruder R, Luczak H (2018) Gruppen- und Teamarbeit. In: Schlick C, Bruder R, Luczak H (eds) Arbeitswissenschaft, 4th edn. Springer Vieweg, Berlin, pp 681-728

Schmalz U, Spinler S, Ringbeck J (2021) Lessons learned from a tworound Delphi-based scenario study. MethodsX 8:101179. https:// doi.org/10.1016/j.mex.2020.101179

Sonnentag S, Binnewies C, Mojza EJ (2010) Staying well and engaged when demands are high: the role of psychological detachment. J Appl Psychol 95(5):965-976. https://doi.org/10.1037/a0020032

Spagnolli A, Guardigli E, Orso V, Varotto A, Gamberini L (2014) Measuring user acceptance of wearable symbiotic devices: validation study across application scenarios. In: Jacucci G, Gamberini L, Freeman J, Spagnolli A (eds) Symbiotic interaction Third international workshop, Symbiotic 2014, Helsinki, October 30-31, 2014. Lecture notes in computer science Information systems and applications, incl. Internet/web, and HCI, 8820. Springer, Cham (proceedings)

Stegmann S, van Dick R, Ullrich J, Charalambous J, Menzel B, Egold N, Wu TT-C (2010) Der work design questionnaire. Z Arbeits Organisationspsychol 54(1):1-28. https://doi.org/10.1026/ 0932-4089/a000002

Steigleder S (2008) Die strukturierende qualitative Inhaltsanalyse im Praxistest. Eine konstruktiv kritische Studie zur Auswertungsmethodik von Philipp Mayring. Tectum, Marburg (Zugl.: Trier, Univ., Diss., 2007)

Syberfeldt A, Danielsson O, Gustavsson P (2017) Augmented reality smart glasses in the smart factory. Product evaluation guidelines and review of available products. IEEE Access 5:9118-9130. https://doi.org/10.1109/ACCESS.2017.2703952

Szalavetz A (2021) Digital technologies and the nature and routine intensity of work. Evidence from Hungarian manufacturing subsidiaries. Working Paper, 2021.01. European trade union institute, Brussels

Tortoriello M, Reagans R, McEvily B (2012) Bridging the knowledge gap. The influence of strong ties, network cohesion, and network 
range on the transfer of knowledge between organizational units. Organ Sci 23(4):1024-1039. https://doi.org/10.1287/orsc.1110. 0688

Tossell CC, Kortum P, Shepard C, Rahmati A, Zhong L (2012) An empirical analysis of smartphone personalisation. Measurement and user variability. Behav Inf Technol 31(10):995-1010. https:// doi.org/10.1080/0144929X.2012.687773

Ulich E (1993) CIM - eine integrative Gestaltungsaufgabe im Spannungsfeld von Mensch, Technik und Organisation. In: Cyranek G, Ulich E (eds) CIM. Herausforderung an Mensch, Technik, Organisation, vol 1. Verl. der Fachvereine, Zürich, pp 29-44

Bin Wang, Yukun L, Parker SK (2020) How does the use of information communication technology affect individuals? A work design perspective. Acad Manag Ann 14(2):695-725. https://doi.org/10. 5465/annals.2018.0127

Waschull S, Bokhorst JAC, Molleman E, Wortmann JC (2020) Work design in future industrial production. Transforming towards cyber-physical systems. Comput Ind Eng 139(3):105679. https:// doi.org/10.1016/j.cie.2019.01.053
Wegman LA, Hoffman BJ, Carter NT, Twenge JM, Guenole N (2018) Placing job characteristics in context. Cross-temporal metaanalysis of changes in job characteristics since 1975. J Manage 44(1):352-386. https://doi.org/10.1177/0149206316654545

Widuckel W (2015) Arbeitskultur 2020 - Herausforderungen für die Zukunft der Arbeit. In: Widuckel W, de Molina K, Ringlstetter MJ, Frey D (eds) Arbeitskultur 2020. Springer, Wiesbaden, pp 27-44

Williams R, Edge D (1996) The social shaping of technology. Res Policy 25(6):865-899. https://doi.org/10.1016/0048-7333(96)008852

Wilson JM, Straus SG, McEvily B (2006) All in due time. The development of trust in computer-mediated and face-to-face teams. Organ Behav Hum Decis Process 99(1):16-33. https://doi.org/10. 1016/j.obhdp.2005.08.001

Worden K, Haywood J, Bullough WA (eds) (2003) Smart technologies. World Scientific, 